Article

\title{
A Hybrid Method for Generation of Typical Meteorological Years for Different Climates of China
}

\author{
Haixiang Zang *, Miaomiao Wang, Jing Huang, Zhinong Wei and Guoqiang Sun \\ College of Energy and Electrical Engineering, Hohai University, Nanjing 211100, China; \\ hhuwangmiaomiao@163.com (M.W.); Huang_jing_81@126.com (J.H.); wzn_nj@263.net (Z.W.); \\ hhusunguoqiang@163.com (G.S.) \\ * Correspondence: zanghaixiang@hhu.edu.cn; Tel.: +86-25-5809-9081
}

Academic Editor: John Boland

Received: 22 October 2016; Accepted: 17 December 2016; Published: 21 December 2016

\begin{abstract}
Since a representative dataset of the climatological features of a location is important for calculations relating to many fields, such as solar energy system, agriculture, meteorology and architecture, there is a need to investigate the methodology for generating a typical meteorological year (TMY). In this paper, a hybrid method with mixed treatment of selected results from the Danish method, the Festa-Ratto method, and the modified typical meteorological year method is proposed to determine typical meteorological years for 35 locations in six different climatic zones of China (Tropical Zone, Subtropical Zone, Warm Temperate Zone, Mid Temperate Zone, Cold Temperate Zone and Tibetan Plateau Zone). Measured weather data (air dry-bulb temperature, air relative humidity, wind speed, pressure, sunshine duration and global solar radiation), which cover the period of 1994-2015, are obtained and applied in the process of forming TMY. The TMY data and typical solar radiation data are investigated and analyzed in this study. It is found that the results of the hybrid method have better performance in terms of the long-term average measured data during the year than the other investigated methods. Moreover, the Gaussian process regression (GPR) model is recommended to forecast the monthly mean solar radiation using the last 22 years (1994-2015) of measured data.
\end{abstract}

Keywords: solar energy; solar radiation; typical meteorological year (TMY); climatic zones

\section{Introduction}

It is known that China is the most populous country in the world, with a population of more than 1.3 billion and covering an area of over 9.6 million $\mathrm{km}^{2}$. The fact that China ranks as the second largest consumer of energy raises concern about energy conservation and environmental protection [1-3]. Solar energy, as a kind of renewable energy, is more energy-efficient and eco-friendly than oil and coal [4-6]. Solar energy has received much attention in China as it is considered to meet a portion of China's energy demand. Quite a few weather files have been developed over the years for acquiring representative meteorological data, which is used to predict the annual performance of solar energy systems and evaluate building energy simulation [7-9]. These weather files, known as test reference year (TRY) [10,11], design reference year (DRY) [12], and typical meteorological year (TMY) [13-15], are a representative database for one year and consist of a concatenation of 12 individual months selected from different years over the measured data duration.

The American Society of Heating, Refrigerating and Air-Conditioning Engineers (ASHRAE) has built up a simple selection procedure to gather the climatic information in a TRY [16]. In the process of a TRY selection, only one meteorological variable—dry-bulb temperature-is considered. More crucially, the available years, which contain months with extremely high or extremely low dry-bulb temperature, are ruled out until only one year remains, which is chosen to be the representative month of the TRY. 
This selection procedure may lead to an unrepresentative database, so it is not recommended for use in research of long-term performance of solar energy systems performed by the ASHRAE [17]. DRY is a modified version of the TRY in which it adjusts main meteorological variables (e.g., dry-bulb temperature, air relative humidity, and solar radiation) by substituting some days from other years for certain days in the same month.

Sharing a common feature with TRY, in that it uses real and effective weather data, TMY is widely accepted by most researchers. During the process of generating a TMY, 12 typical meteorological months are determined by applying the weather data from a long time period. In addition, various methods have been reported by numerous researchers in the literature for forming TMYs. Such methods include the Sandia method [18-20], the Crow method [21], the Danish method [22], the Festa-Ratto method [23], the Miquel-Bilbao method [24], and the Gazela-Mathioulakis method [25]. Among them, the Sandia method, proposed by Hall et al. [20], is the most commonly-used one. Efforts have also been put into generating TMYs for some cities with a different number of meteorological indices and assigned weightings by Pissimanis et al. [26,27], Skeiker [12], Chan et al. [28,29], Argiriou et al. [30], Kalogirou [13], and Yang et al. [11,31].

Recently, several studies have focused on obtaining the TMYs for different locations in China. In accordance with Zhang [32], the typical meteorological database for 57 Chinese locations was developed, but because no data exists on solar radiation in the observations, a method to estimate solar radiation with dry bulb temperature difference, relative humidity, total cloud cover and wind speed was developed. Chow et al. [33] and Chan et al. [29], respectively, provide TMYs for Hong Kong. Chow et al. [33] also applied the method to Macau and conducted analysis of typical weather year files. Jiang [34], $\mathrm{Xu}$, and Zang [35] generated TMYs only for eight representative locations in China.

In this study, TMYs are composed of a mixture of the results of the Danish method, the Festa-Ratto method, and the modified typical meteorological year method for 35 representative locations in six climatic zones in China. The three methods are employed firstly with a set of weather data covering at least 10 years. Then a comparison between the results of the three methods and the long-term measured data are implemented by the value of ERMSD. Finally, those months that have meteorological data closest to long-term weather observations (the value of ERMSD is smallest for each individual month) are selected to generate a TMY for a certain city.

\section{Climatic Zones and Data Collection}

China is a vast country with a varied climate $[2,36]$. Among the different ways to classify the climatic types in China, the temperature-strip method is recommended in this paper. According to this method $[37,38]$, it can be divided into six climatic types based on annual accumulated temperature, which is obtained from the summation of the daily mean temperatures over $10{ }^{\circ} \mathrm{C}$ within a year, namely Tropical Zone (TZ) $\left(>8000^{\circ} \mathrm{C}\right)$, Subtropical Zone (SZ) $\left(4500{ }^{\circ} \mathrm{C}-8000{ }^{\circ} \mathrm{C}\right)$, Warm Temperate Zone (WTZ) $\left(3400^{\circ} \mathrm{C}-4500{ }^{\circ} \mathrm{C}\right)$, Mid Temperate Zone (MTZ) $\left(1600{ }^{\circ} \mathrm{C}-3400{ }^{\circ} \mathrm{C}\right)$, Cold Temperate Zone $(\mathrm{CTZ})\left(<1600^{\circ} \mathrm{C}\right)$ and the special zone-Tibetan Plateau Zone (TPZ). Figure 1 shows a general layout of the six major climate areas.

To cover the six major climate types, a total of 35 meteorological stations are taken into account in this study. The weather data (including daily air dry-bulb temperature, relative humidity, wind speed, pressure, sunshine duration and global solar radiation) in these cities are available from China meteorological stations. For each station, measured weather data cover at least 10 years during a period from 1 January 1994 to 31 December 2015. The 35 stations cover longitudes from $75^{\circ} 59^{\prime} \mathrm{E}$ (Kashgar) to $130^{\circ} 17^{\prime} \mathrm{E}$ (Jiamusi), latitudes ranging from $18^{\circ} 14^{\prime} \mathrm{N}$ (Sanya) to $53^{\circ} 28^{\prime} \mathrm{N}$ (Mohe), and have considerably variable altitude from $2.5 \mathrm{~m}$ (Tianjin) to $4507 \mathrm{~m}$ (Nagqu).

Information on the selected 35 typical stations is given in Table 1. 


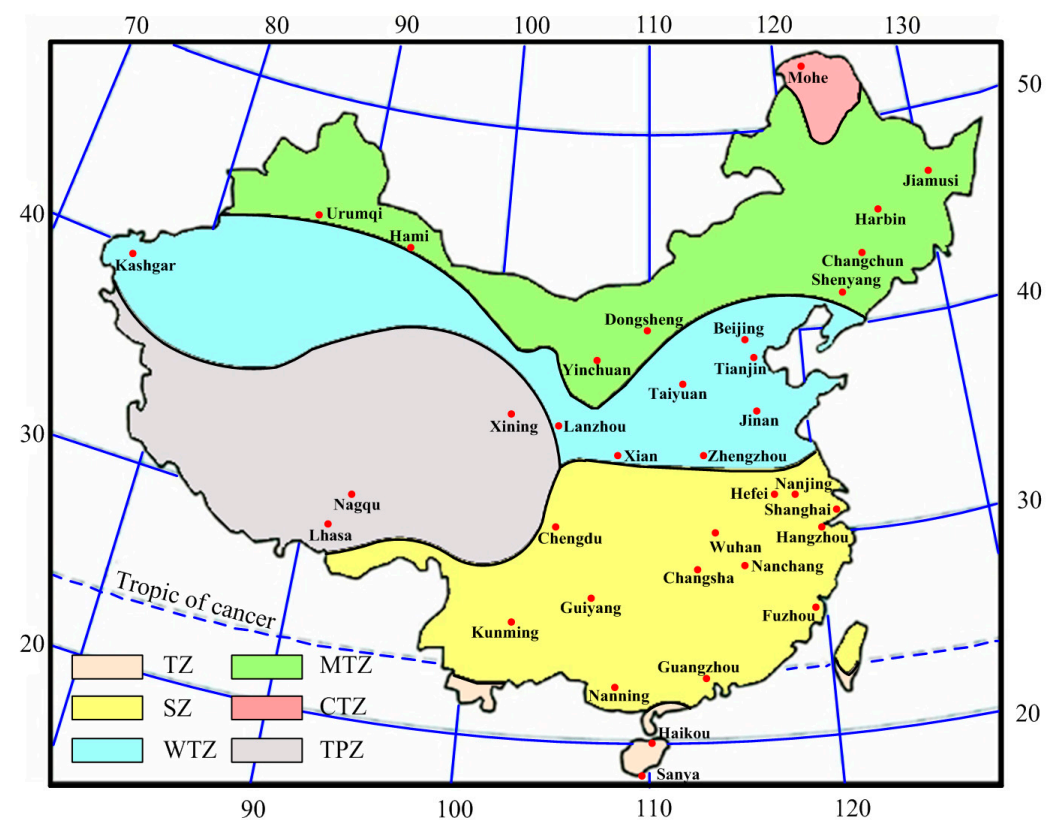

Figure 1. A general layout of the six major climates across China. $\mathrm{TZ}=$ Tropical Zone; $\mathrm{SZ}=$ Subtropical Zone; WTZ = Warm Temperate Zone; MTZ = Mid Temperate Zone; CTZ = Cold Temperate Zone; PZ = Tibetan Plateau Zone [1].

Table 1. The main information of the 35 cities selected for the present study.

\begin{tabular}{|c|c|c|c|c|c|c|c|}
\hline Number & Location & Latitude (N) & Longitude (E) & Elevation (m) & Climates & Period & Total Years \\
\hline 1 & Haikou & $20^{\circ} 02^{\prime}$ & $110^{\circ} 21^{\prime}$ & 14 & $\mathrm{TZ}$ & 1994-2015 & 22 \\
\hline 2 & Sanya & $18^{\circ} 14^{\prime}$ & $109^{\circ} 31^{\prime}$ & 6 & $\mathrm{TZ}$ & 1994-2015 & 22 \\
\hline 3 & Changsha & $28^{\circ} 13^{\prime}$ & $112^{\circ} 55^{\prime}$ & 68 & SZ & 1994-2015 & 22 \\
\hline 4 & Chengdu & $30^{\circ} 40^{\prime}$ & $104^{\circ} 01^{\prime}$ & 506 & SZ & 1994-2003 & 10 \\
\hline 5 & Fuzhou & $26^{\circ} 05^{\prime}$ & $119^{\circ} 17^{\prime}$ & 84 & SZ & 1994-2015 & 22 \\
\hline 6 & Guangzhou & $23^{\circ} 10^{\prime}$ & $113^{\circ} 20^{\prime}$ & 41 & SZ & 1994-2015 & 22 \\
\hline 7 & Guiyang & $26^{\circ} 35^{\prime}$ & $106^{\circ} 44^{\prime}$ & 1224 & SZ & 1994-2013 & 20 \\
\hline 8 & Hangzhou & $30^{\circ} 14^{\prime}$ & $120^{\circ} 10^{\prime}$ & 42 & SZ & 1994-2015 & 22 \\
\hline 9 & Hefei & $31^{\circ} 52^{\prime}$ & $117^{\circ} 14^{\prime}$ & 28 & SZ & 1994-2015 & 22 \\
\hline 10 & Kunming & $25^{\circ} 01^{\prime}$ & $102^{\circ} 41^{\prime}$ & 1892 & SZ & 1994-2015 & 22 \\
\hline 11 & Nanchang & $28^{\circ} 36^{\prime}$ & $115^{\circ} 55^{\prime}$ & 47 & SZ & 1994-2015 & 22 \\
\hline 12 & Nanjing & $32^{\circ} 00^{\prime}$ & $118^{\circ} 48^{\prime}$ & 7 & SZ & 1994-2015 & 22 \\
\hline 13 & Nanning & $22^{\circ} 38^{\prime}$ & $108^{\circ} 13^{\prime}$ & 122 & SZ & 1994-2015 & 22 \\
\hline 14 & Shanghai & $31^{\circ} 24^{\prime}$ & $121^{\circ} 29^{\prime}$ & 6 & SZ & 1994-2015 & 22 \\
\hline 15 & Wuhan & $30^{\circ} 37^{\prime}$ & $114^{\circ} 08^{\prime}$ & 23 & SZ & 1994-2015 & 22 \\
\hline 16 & Beijing & $39^{\circ} 48^{\prime}$ & $116^{\circ} 28^{\prime}$ & 31 & WTZ & 1994-2015 & 22 \\
\hline 17 & Jinan & $36^{\circ} 36^{\prime}$ & $117^{\circ} 03^{\prime}$ & 170 & WTZ & 1994-2015 & 22 \\
\hline 18 & Kashgar & $39^{\circ} 28^{\prime}$ & $75^{\circ} 59^{\prime}$ & 1289 & WTZ & 1994-2015 & 22 \\
\hline 19 & Lanzhou & $36^{\circ} 03^{\prime}$ & $103^{\circ} 53^{\prime}$ & 1517 & WTZ & 1994-2003 & 10 \\
\hline 20 & Taiyuan & $37^{\circ} 47^{\prime}$ & $112^{\circ} 33^{\prime}$ & 778 & WTZ & 1994-2015 & 22 \\
\hline 21 & Tianjin & $39^{\circ} 05^{\prime}$ & $117^{\circ} 04^{\prime}$ & 3 & WTZ & 1994-2015 & 22 \\
\hline 22 & Xian & $34^{\circ} 18^{\prime}$ & $108^{\circ} 56^{\prime}$ & 398 & WTZ & 1994-2004 & 11 \\
\hline 23 & Zhengzhou & $34^{\circ} 43^{\prime}$ & $113^{\circ} 39^{\prime}$ & 110 & WTZ & 1994-2015 & 22 \\
\hline 24 & Changchun & $43^{\circ} 54^{\prime}$ & $125^{\circ} 13^{\prime}$ & 237 & MTZ & 1994-2015 & 22 \\
\hline 25 & Dongsheng & $39^{\circ} 50^{\prime}$ & $109^{\circ} 59^{\prime}$ & 1460 & MTZ & 1994-2015 & 22 \\
\hline 26 & Hami & $42^{\circ} 49^{\prime}$ & $93^{\circ} 31^{\prime}$ & 737 & MTZ & 1994-2015 & 22 \\
\hline 27 & Harbin & $45^{\circ} 45^{\prime}$ & $126^{\circ} 46^{\prime}$ & 142 & MTZ & 1994-2015 & 22 \\
\hline 28 & Jiamusi & $46^{\circ} 49^{\prime}$ & $130^{\circ} 17^{\prime}$ & 81 & MTZ & 1994-2015 & 22 \\
\hline 29 & Shenyang & $41^{\circ} 44^{\prime}$ & $123^{\circ} 27^{\prime}$ & 45 & MTZ & 1994-2015 & 22 \\
\hline 30 & Urumqi & $43^{\circ} 47^{\prime}$ & $87^{\circ} 39^{\prime}$ & 935 & MTZ & 1994-2015 & 22 \\
\hline 31 & Yinchuan & $38^{\circ} 29^{\prime}$ & $106^{\circ} 13^{\prime}$ & 1111 & MTZ & 1994-2015 & 22 \\
\hline 32 & Mohe & $53^{\circ} 28^{\prime}$ & $122^{\circ} 31^{\prime}$ & 433 & $\mathrm{CTZ}$ & 1997-2007 & 11 \\
\hline 33 & Lhasa & $29^{\circ} 40^{\prime}$ & $91^{\circ} 08^{\prime}$ & 3649 & $\mathrm{TPZ}$ & 1994-2015 & 22 \\
\hline 34 & Nagqu & $31^{\circ} 29^{\prime}$ & $92^{\circ} 04^{\prime}$ & 4507 & TPZ & 1994-2015 & 22 \\
\hline 35 & Xining & $36^{\circ} 43^{\prime}$ & $101^{\circ} 45^{\prime}$ & 2295 & TPZ & 1994-2015 & 22 \\
\hline
\end{tabular}


For the data shown in Table 1, missing and invalid measurements account for $0.32 \%$ of the database. Using interpolation, the missing and invalid measurements are usually replaced with the values for previous or subsequent days. Moreover, if more than 5 days' measured data are not available in a month, the month will be eliminated from the database [30].

\section{Description of Methodologies for TMY Generation}

It is well known that the typical meteorological year can be obtained through a number of methods, like the Danish method, the Festa-Ratto method, the typical meteorological year method, etc. In this part, the three methods are introduced in their original form with some variations in selection procedures. In view of the actual situation in China and the characteristics of solar energy systems, different meteorological indices are applied in this paper. In addition, a hybrid method is proposed aiming for generating TMY for 35 stations in China. The TMY which is available from the hybrid method has minimal differences from long-term average measured data in every month and is selected from a mixture of the results from the three methods.

\subsection{The Danish Method}

The Danish method was initially proposed by Lund and Eidorff [39], and several researchers, such as Janjai and Deeyai [18], and Skeiker [19], have contributed to its improvement and promotion. According to this method, seven daily meteorological parameter indices are cited for selection of typical meteorological months (TMMs) for each of the selected 35 meteorological stations: maximum air dry-bulb temperature, mean air dry-bulb temperature, mean air relative humidity, mean wind speed, mean pressure, sunshine duration and global solar radiation. This is an approach that uses a 3-step procedure to select individual months from different years during the measuring period.

In the first step, by considering the characteristics of solar energy systems, only three daily meteorological parameter indices are taken into account, namely, maximum air dry-bulb temperature, mean air dry-bulb temperature, and global solar radiation.

To eliminate seasonal variation, daily meteorological parameter indices are converted into daily residuals with regard to the smoothed daily long-term values obtained by Fourier analysis:

$$
Y(y, m, d)=x(y, m, d)-\mu_{x}(m, d)
$$

where $Y(y, m, d)$ is the residual of meteorological parameter index $x$ for year $y$, month $m$, and day $d$, with respect to the smoothed daily long-term mean $\mu_{x}(m, d)$ as calculated over the available years.

For each individual month, absolute values for the standardized mean $f_{\mu}(y, m)$ and the standardized standard deviation $f_{\sigma}(y, m)$ of the residuals obtained using Equation (1) are calculated as follows:

$$
\begin{aligned}
& f_{\mu}(y, m)=\left|\frac{\mu_{Y}(y, m)-\mu_{\mu Y}(y)}{\sigma_{\mu Y}(y)}\right| \\
& f_{\sigma}(y, m)=\left|\frac{\sigma_{Y}(y, m)-\mu_{\sigma Y}(y)}{\sigma_{\sigma Y}(y)}\right|
\end{aligned}
$$

where $\mu_{Y}(y, m)$ is the monthly mean and $\sigma_{Y}(y, m)$ is the standard deviation of the $Y(y, m, d)$ for the year $y$, month $m ; \mu_{\mu \curlyvee}(y)$ and $\sigma_{\mu \curlyvee}(y)$ are the mean and standard deviation of $\mu_{\Upsilon}(y, m)$ for year $y ; \mu_{\sigma Y}(y)$, $\sigma_{\sigma Y}(y)$ are the mean and standard deviation of $\sigma_{Y}(y, m)$ for year $y$. Thus, each individual month is characterized by six values, while three meteorological parameter indices are used in all.

Then, the six values of $f_{\mu}(y, m)$ and $f_{\sigma}(y, m)$ for each individual month are compared to select the maximal value $\left(f_{\max }(y, m)\right)$ :

$$
f_{\max }(y, m)=\max \left\{f_{\mu}(y, m, j), f_{\sigma}(y, m, j)|1 \leq j \leq 3|\right\}
$$


where $(y, m, j)$ represents the standardized mean or standardized standard deviation for meteorological parameter index $j$ for year $y$, month $m$. For month $m$, the first three months will be selected as priority candidate months when the months during available years are ranked in ascending order according to the value for $f_{\max }(y, m)$.

In the second step, the long-term and short-term mean values of the seven daily meteorological parameter indices are calculated. If the short-term mean value of parameter index $x$ for year $y$, month $m$ differs by more than one standard deviation from the long-term mean value of the respective month, the month scores 0 . Otherwise, a score of 1 is given to the month. The final score of each individual month is the sum of the scores, with a maximum value of 7 . In the last step, among the three priority candidate months, the month with the highest score is included in the TMY.

\subsection{The Festa-Ratto Method}

The Festa-Ratto method is a modification of the Danish method and involves a rather complicated statistical treatment of the data. For the purposes of this study, seven daily meteorological parameter indices which are similar with that in the Danish method are utilized for this method.

In step 1 , the daily meteorological parameter indices are converted into standardized residuals with respect to the smoothed long-term values, obtained as follows:

$$
X(y, m, d)=\frac{x(y, m, d)-\mu_{x}(m, d)}{\sigma_{x}(m, d)}
$$

where $X(y, m, d)$ is the standardized residual of meteorological parameter index $x$, for year $y$, month $m$, and day $d$, with respect to the smoothed long-term mean $\mu_{x}(m, d)$ and standard deviation $\sigma_{x}(m, d)$ as calculated for the available years.

In step 2, the first-order product of the standardized residuals is calculated:

$$
z(y, m, d)=X(y, m, d) \cdot X(y, m, d+1)
$$

The first-order products $z(y, m, d)$ are converted into standardized residuals with respect to the smoothed long-term values using:

$$
Z(y, m, d)=\frac{z(y, m, d)-\mu_{z}(m, d)}{\sigma_{z}(m, d)}
$$

where $Z(y, m, d)$ is the standardized residual of new parameter index $z$ for year $y$, month $m$, and day $d$, with respect to the smoothed long-term mean $\mu_{z}(m, d)$ and standard deviation $\sigma_{z}(m, d)$ as calculated for the available years. Since the number of daily meteorological parameters involved is 7 , there are 7 new parameter indices $Z$ created in total.

In step 3, the short-term mean value $\mu_{X}(y, m)$ and standard deviation $\sigma_{X}(y, m)$ for standardized residual $X(y, m, d)$ for year $y$, month $m$ are calculated. At the same time, the long-term mean value $\mu_{\mu X}(m)$ and standard deviation $\sigma_{\mu X}(m)$ for month $m$ during the available years are obtained based on $\mu_{X}(y, m)$. A similar procedure is carried out to obtain $\mu_{Z}(y, m), \sigma_{Z}(y, m), \mu_{\mu Z}(m)$, and $\sigma_{\mu Z}(m)$. The short-term and long-term cumulative distribution function $(C D F)$ for $X(y, m, d)$ and $Z(y, m, d)$ are also determined.

Based on the above results, the statistical distance between the short-term and the long-term mean values $d_{a v}$ and standard deviations $d_{s d}$, as well as the Kolmogorov-Smirnov parameter, $d_{k s}$, are calculated for each $X$ and $Z$ parameter and each individual month as follows:

$$
\begin{aligned}
& d_{a v, X}(y, m)=\left|\mu_{X}(y, m)-\mu_{\mu X}(m)\right| \\
& d_{a v, Z}(y, m)=\left|\mu_{Z}(y, m)-\mu_{\mu Z}(m)\right| \\
& d_{s d, X}(y, m)=\left|\sigma_{X}(y, m)-\sigma_{\mu X}(m)\right|
\end{aligned}
$$




$$
\begin{gathered}
d_{s d, Z}(y, m)=\left|\sigma_{Z}(y, m)-\sigma_{\mu Z}(m)\right| \\
d_{k s, X}(y, m)=\max \left|C D F_{y, m}(X)-C D F_{m}(X)\right| \\
d_{k s, Z}(y, m)=\max \left|C D F_{y, m}(Z)-C D F_{m}(Z)\right|
\end{gathered}
$$

Next, the composite distances $d_{X}(y, m)$ and $d_{Z}(y, m)$ for each daily meteorological parameter index are calculated using the following equations:

$$
\begin{aligned}
& d_{X}(y, m)=(1-a-b) \cdot d_{k s . X}(y, m)+a \cdot d_{a v . X}(y, m)+b \cdot d_{s d . X}(y, m) \\
& d_{Z}(y, m)=(1-a-b) \cdot d_{k s . Z}(y, m)+a \cdot d_{a v . Z}(y, m)+b \cdot d_{s d . Z}(y, m)
\end{aligned}
$$

where $a=b \approx 0.1$.

In step 4, for each month, 14 sets of distances are obtained from Equations (14) and (15), and the maximum value is sorted to form a new set of distances for that month. Then the month with the minimum distance in the new set is selected to be a member of the TMY. This min-max approach is shown as follows:

$$
d_{\min \cdot \max }(m, 1)=\min \left\{\max \left[d_{X}(y, m, j), d_{Z}(y, m, j)\right]|1 \leq j \leq 7|\right\}
$$

\subsection{The Modified Typical Meteorological Year (TMY) Method}

The TMY method, primarily proposed by Sandia National Laboratories, is one of the most popular methods for determining typical years. In this method, a set of 12 typical meteorological months (TMMs) is selected from a multi-year database using the Finkelstein-Schafer ( $F S$ ) statistical method [40]. Unlike the two methods described above, this method primarily pays attention to eight daily meteorological parameter indices to select typical months: maximum air dry-bulb temperature, mean air dry-bulb temperature, minimum air dry-bulb temperature, mean air relative humidity, minimum air relative humidity, maximum wind speed, mean wind speed, and global solar radiation. The selection procedure for the TMY consists of two steps.

In the first step, for each month of the different years, five candidate months having a $C D F$ closest to the respective long-term distributions are selected. This selection is based on the variation between annual $C D F$ and long-term $C D F$ for the month in question. Moreover, to measure the variation, an empirical $C D F$ for each meteorological parameter is determined using the following function:

$$
S_{n}(x)=\left\{\begin{array}{ccc}
0 & \text { for } & x<x_{1} \\
(i-0.5) / n & \text { for } & x_{i} \leq x<x_{i+1} \\
1 & \text { for } & x \geq x_{n}
\end{array}\right.
$$

where $S_{n}(x)$ is the value of the $C D F$ for parameter index $x ; i$ is the rank order number. $n$ is the total number of meteorological parameters. From its definition, $S_{n}(x)$ is a monotonic increasing function with steps of sizes $1 / n$ occurring at $x_{i}$ and is bounded by 0 and 1 . Then the value of $F S$ statistics of each parameter is obtained using:

$$
F S_{x}(y, m)=\frac{1}{N} \sum_{i=1}^{N}\left|C D F_{m}\left(x_{i}\right)-C D F_{y, m}\left(x_{i}\right)\right|
$$

where $F S_{x}(y, m)$ is the $F S$ statistic for year $y$, month $m ; C D F_{m}$ is the long-term and $C D F_{y, m}$ is the short-term $C D F$ of parameter index $x$ for month $m$; and $N$ is the number of daily readings of the month.

The weighted sum (WS) of the $F S$ statistics is derived by applying weighting factors $W F_{x}$ to the FS statistics values corresponding to each specific month in the selected period: 


$$
\begin{gathered}
W S(y, m)=\frac{1}{M} \sum_{x=1}^{M} W F_{x} \cdot F S_{x}(y, m) \\
\sum_{x=1}^{M} W F_{x}=1
\end{gathered}
$$

where $W S(y, m)$ is the weighted sum of the $F S$ statistics for eight meteorological parameter indices for year $y$, month $m ; W F_{x}$ is the weighting factor for parameter index $x ; M$ is the number of meteorological parameter indices. Furthermore, the five months with lowest WS values are selected to be candidate months.

It is worth mentioning that the weighting factors are essential for choosing TMY from the measured data. In consideration of the fact that this criterion is mainly applied to solar energy systems, global solar radiation gets the highest value among weighting factors. The assigned weighting factors are shown in Table 2.

Table 2. Weighting factors for TMY type.

\begin{tabular}{ccccccc}
\hline Parameter Indices & Ref. [12,26] & {$[\mathbf{1 7 , 3 3}]$} & {$[\mathbf{4 1}]$} & {$[\mathbf{1 3}]$} & [34] & Present Article \\
\hline Max Dry-Bulb Temperature & $1 / 24$ & $5 / 100$ & $1 / 20$ & $1 / 32$ & $1 / 20$ & $1 / 24$ \\
Min Dry-Bulb Temperature & $1 / 24$ & $5 / 100$ & $1 / 20$ & $1 / 32$ & $1 / 20$ & $1 / 24$ \\
Mean Dry-Bulb Temperature & $2 / 24$ & $30 / 100$ & $2 / 20$ & $2 / 32$ & $3 / 20$ & $3 / 24$ \\
Range Dry-Bulb Temperature & - & - & - & $1 / 32$ & - & - \\
Max Relative Humidity & $1 / 24$ & $2.5 / 100$ & $1 / 20$ & $1 / 32$ & - & - \\
Min Relative Humidity & $1 / 24$ & $2.5 / 100$ & $1 / 20$ & $1 / 32$ & $1 / 20$ & $1 / 24$ \\
Mean Relative Humidity & $2 / 24$ & $5 / 100$ & $2 / 20$ & $2 / 32$ & $2 / 20$ & $2 / 24$ \\
Range Relative Humidity & - & - & - & $1 / 32$ & - & - \\
Max Wind Speed & $2 / 24$ & $5 / 100$ & $1 / 20$ & $1 / 32$ & $1 / 20$ & $2 / 24$ \\
Min Wind Speed & - & - & - & $1 / 32$ & - & - \\
Mean Wind Speed & $2 / 24$ & $5 / 100$ & $1 / 20$ & $2 / 32$ & $1 / 20$ & $2 / 24$ \\
Range Wind Speed & - & - & - & $1 / 32$ & - & - \\
Mean Wind direction & - & - & - & $1 / 32$ & - & - \\
Global Solar Radiation & $12 / 24$ & $40 / 100$ & $5 / 20$ & $8 / 32$ & $5 / 20$ & $12 / 24$ \\
Direct Solar Radiation & - & - & $5 / 20$ & $8 / 32$ & $5 / 20$ & - \\
\hline
\end{tabular}

In the second stage, among various methods $[10,25]$ for selecting TMMs from the five candidate months, a simpler selection process [26,42], starting with calculation of the root mean square difference (RMSD), is adopted. The RMSD is defined as follows:

$$
R M S D=\left[\frac{\sum_{k=1}^{N}\left(H_{y, m, k}-H_{m a}\right)^{2}}{N}\right]^{1 / 2}
$$

where $R M S D$ is the root mean square difference of global solar radiation; $H_{y, m, k}$ is the value of daily global solar radiation for year $y$, month $m$ and day $k ; H_{m a}$ is the long-term mean value of global solar radiation for the month $m$; and $N$ is the number of daily readings of the month. The month with the minimum RMSD is finally selected as the TMM.

\subsection{TMY Selection Procedure}

The final TMY selection is based on the hybrid method, by which the results of the Danish method, the Festa-Ratto method, and the modified typical meteorological year method are combined. After obtaining TMYs using the aforementioned methods, those results having the minimum differences from long-term average measured data for each month will be used to form a typical meteorological year. The selection procedure is described as below: 
First, for the three TMYs determined using the above methods, the values of indices 1, 2, 3, 4, which correspondingly represent the daily average values of global solar radiation, air dry-bulb temperature, mean air relative humidity, and wind speed, are compared with daily mean long-term average measured data for the same parameter indices by applying RMSD. The definition of RMSD for global solar radiation is shown in Equation (21), and that for other indices likes it.

Next, the sum of yearly values of RMSD (SYRMSD) are respectively calculated for the four mentioned parameter indices for each method:

$$
S Y R M S D_{p}=\sum_{i=1}^{12} R M S D_{p}^{i}
$$

where $p$ is the number of the index; $i$ represents the month number.

Finally, the highest ranked one among the results of three months for every month, in ascending order of the ERMSD, is used in the TMY. The ERMSD parameter is defined using this equation:

$$
E R M S D^{i}=\frac{R M S D_{1}^{i}}{S Y R M S D_{1}}+\frac{R M S D_{2}^{i}}{S Y R M S D_{2}}+\frac{R M S D_{3}^{i}}{S Y R M S D_{3}}+\frac{R M S D_{4}^{i}}{S Y R M S D_{4}}
$$

where $i$ is the number of the month; $R M S D_{1}{ }^{i}$ is the root mean square difference of index 1 for month $i$; $S Y R M S D_{1}$ is mean yearly values of $R M S E$ of index $1 ; R M S D_{2}{ }^{i}$ and $S Y R M S D_{2}$ are for index $2 ; R M S D_{3}{ }^{i}$ and $S Y R M S D_{3}$ are for index 3 ; and $R M S D_{4}{ }^{i}$ and $S Y R M S D_{4}$ are for index 4.

\section{Performance Comparison}

Application of the selection procedures described above and the data at the 35 stations provided in Table 1 generates the TMYs for 35 stations. Table 3 provides the TMYs data obtained using the Danish method (TMY_D), the Festa-Ratto method (TMY_F), and the modified typical meteorological year method (TMY_M) for six stations.

Table 3. TMYs obtained using the Danish method, Festa-Ratto method, and modified typical

\begin{tabular}{|c|c|c|c|c|c|c|c|c|c|c|c|c|c|}
\hline \multirow{2}{*}{ Station } & \multirow{2}{*}{ Method } & \multicolumn{12}{|c|}{ Month } \\
\hline & & Jan. & Feb. & Mar. & Apr. & May & Jun. & Jul. & Aug. & Sep. & Oct. & Nov. & Dec. \\
\hline \multirow{3}{*}{$\begin{array}{l}\text { Haikou } \\
\text { (TZ) }\end{array}$} & TMY_D & 1994 & 2006 & 1997 & 1998 & 2004 & 2010 & 1998 & 2003 & 2001 & 1999 & 2003 & 2009 \\
\hline & TMY_F & 1996 & 1998 & 1999 & 1999 & 1994 & 2003 & 2000 & 1999 & 2000 & 2000 & 1996 & 2015 \\
\hline & TMY_M & 1994 & 1994 & 2001 & 1998 & 2004 & 2000 & 1998 & 1996 & 2000 & 1996 & 1996 & 1998 \\
\hline \multirow{3}{*}{$\begin{array}{c}\text { Shanghai } \\
\text { (SZ) }\end{array}$} & TMY_D & 1994 & 2003 & 2000 & 2000 & 2004 & 1995 & 1996 & 2005 & 2013 & 1997 & 1996 & 2009 \\
\hline & TMY_F & 1996 & 1997 & 2012 & 1997 & 2004 & 2007 & 2010 & 2005 & 1994 & 2013 & 2014 & 2006 \\
\hline & TMY_M & 2010 & 2011 & 1995 & 2000 & 2000 & 2003 & 2012 & 2005 & 2013 & 1997 & 1999 & 2011 \\
\hline \multirow{3}{*}{$\begin{array}{l}\text { Zhengzhou } \\
\text { (WTZ) }\end{array}$} & TMY_D & 1998 & 1997 & 2015 & 2009 & 2015 & 2013 & 2002 & 2012 & 2000 & 2011 & 1999 & 1997 \\
\hline & TMY_F & 1997 & 1994 & 1995 & 2007 & 2010 & 2001 & 1999 & 2009 & 2000 & 2011 & 1999 & 2006 \\
\hline & TMY_M & 1997 & 1998 & 2013 & 2007 & 2015 & 1998 & 2009 & 2002 & 2000 & 2008 & 1998 & 1998 \\
\hline \multirow{3}{*}{$\begin{array}{l}\text { Yinchuan } \\
\text { (MTZ) }\end{array}$} & TMY_D & 2010 & 2013 & 2012 & 2003 & 2008 & 2002 & 2015 & 2008 & 2000 & 2013 & 2005 & 2004 \\
\hline & TMY_F & 2010 & 2006 & 2005 & 2012 & 1999 & 1995 & 2007 & 2000 & 2000 & 2010 & 1999 & 2006 \\
\hline & TMY_M & 2007 & 2003 & 2005 & 2007 & 2012 & 2003 & 2007 & 2008 & 1999 & 2003 & 2007 & 2003 \\
\hline \multirow{3}{*}{$\begin{array}{l}\text { Mohe } \\
\text { (CTZ) }\end{array}$} & TMY_D & 2000 & 2004 & 2004 & 2001 & 2003 & 2005 & 2002 & 2007 & 1998 & 2000 & 2005 & 2001 \\
\hline & TMY_F & 2003 & 2007 & 2000 & 1998 & 2005 & 2002 & 2007 & 1999 & 2003 & 2003 & 1999 & 2002 \\
\hline & TMY_M & 2003 & 2000 & 2006 & 2003 & 2004 & 1999 & 2006 & 2006 & 2007 & 2005 & 2005 & 2004 \\
\hline \multirow{3}{*}{$\begin{array}{l}\text { Lhasa } \\
\text { (TPZ) }\end{array}$} & TMY_D & 1998 & 2010 & 2005 & 2005 & 2010 & 1997 & 1999 & 2001 & 2006 & 1999 & 1998 & 2003 \\
\hline & TMY_F & 1994 & 2007 & 2008 & 2008 & 2011 & 2006 & 1999 & 2010 & 2001 & 2010 & 1999 & 2000 \\
\hline & TMY_M & 2001 & 1999 & 2009 & 2008 & 1994 & 1994 & 2014 & 2014 & 2001 & 2000 & 2012 & 2001 \\
\hline
\end{tabular}
meteorological year method for 6 different cities in China.

The selected cities (Haikou, Shanghai, Zhengzhou, Yinchuan, Mohe, and Lhasa) respectively represent the six different climate types (TZ, SZ, WTZ, MTZ, CTZ, and TPZ) and provide a good 
sample of the range of latitude, longitude, and elevation. In Table 3, it can be seen that for each city the TMY comprises 12 individual months selected from different years of the measuring period for each particular method. Taking Lhasa (TPZ) as an example, it is apparent that a year considered typical for a certain month might not be inevitably typical for another month. For instance, January 1994 is selected as a TMM with TMY_F, while February is the one in 2007 in the same TMY. What is more, the composition of TMYs generated using the three methods is not identical for selected cities.

To gain a good understanding of selection patterns, we consider Lhasa again as an example for pictorial display. The values for RMSD of the three methods are computed and separately shown for the four meteorological parameter indices of Lhasa in Figures 2-5. In Figure 2, most of the result for global solar radiation obtained from TMY_M is the smallest for each individual month of the year. At the same time, the air relative humidity result of TMY_M, which is plotted in Figure 4, has greater agreement with those obtained from the measuring period data than do the air relative humidity results from TMY_D and TMY_F for most months of the year. It can be also confirmed from Figures 3 and 5 that the minimum RMSD for dry-bulb temperature and wind speed are respectively produced by TMY_D and TMY_F for the majority of months.

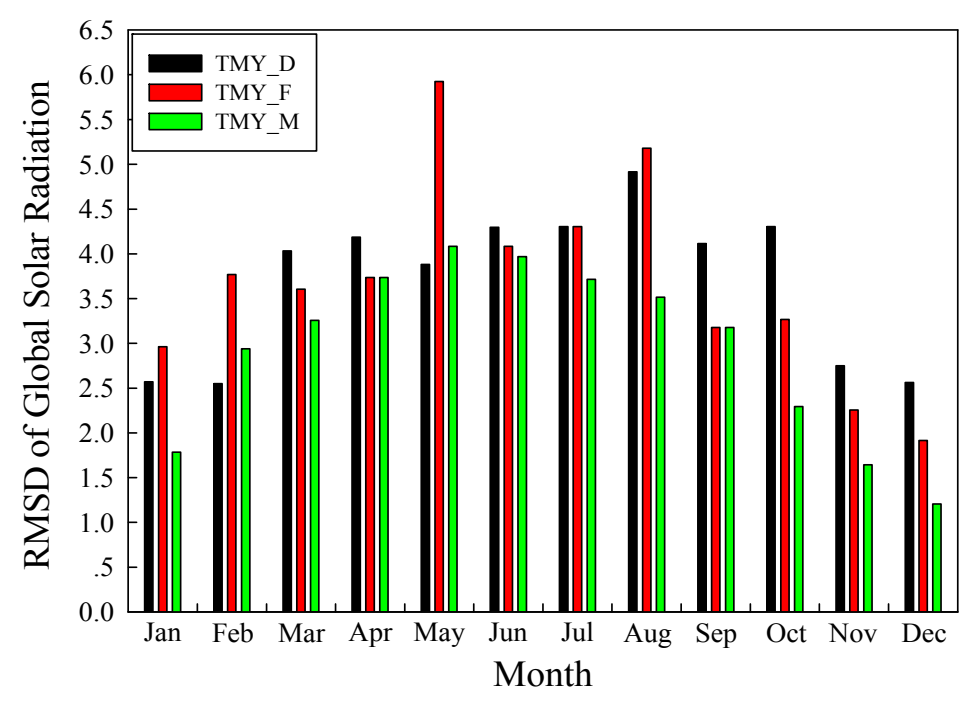

Figure 2. RMSD results of global solar radiation by the three methods in Lhasa.

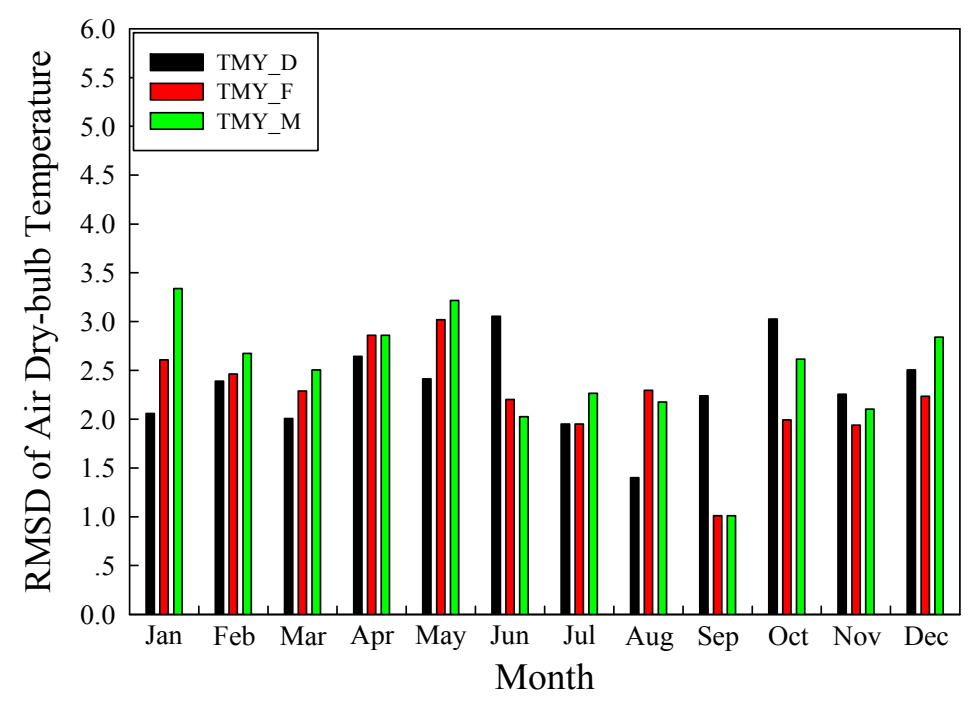

Figure 3. $R M S D$ results of air dry-bulb temperature by the three methods in Lhasa. 


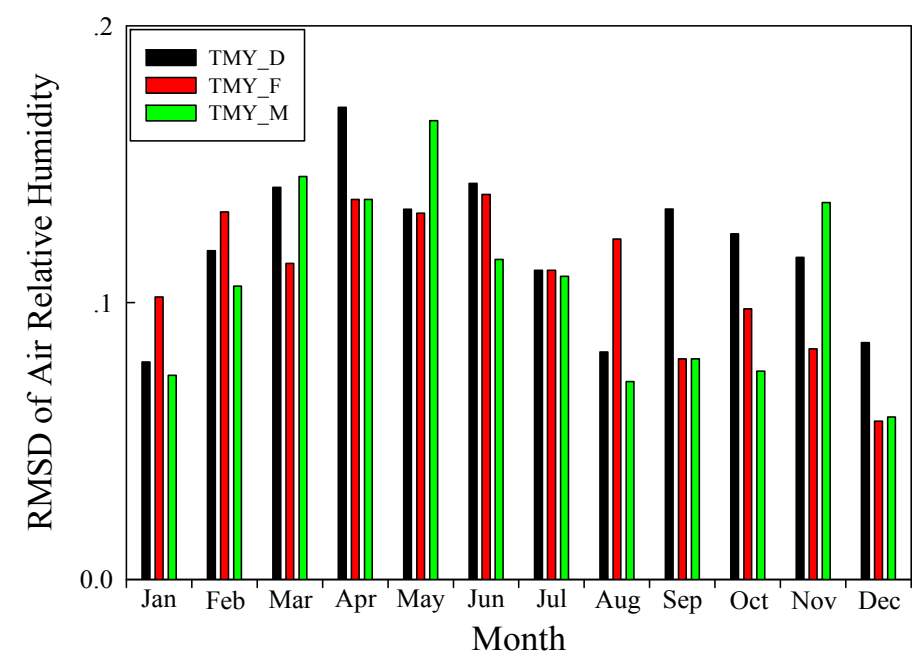

Figure 4. RMSD results of air relative humidity by the three methods in Lhasa.

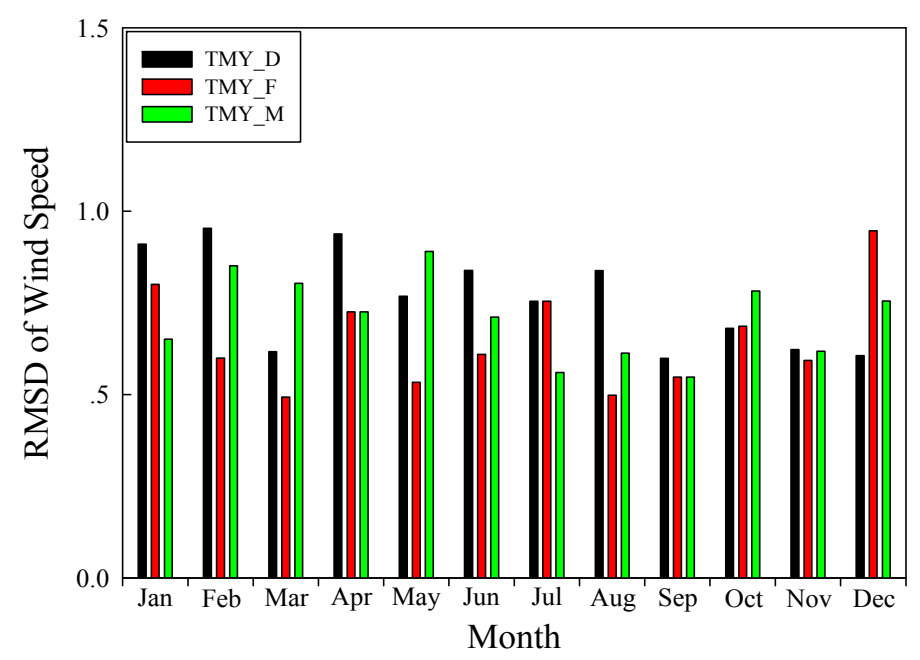

Figure 5. RMSD results of wind speed by the three methods in Lhasa.

Next follows the calculation of the sum of yearly values for RMSD of the four main indices. Table 4 provides the values for ERMSD, which are assigned to the respective months using Equation (22). The ERMSDs often differ from month to month in a typical meteorological year, as well as vary in approach to each month as shown in Table 4. Moreover, the months with the smallest ERMSD values are shown with bold characters. In the end, the selected method for each month is determined by the minimum value of ERMSD. The smaller the ERMSD is, the better agreement will be with the mean measured data over time. The information about ERMSD for each candidate month in Lhasa is tabulated in Table 4. As demonstrated, the numbers printed in bold cells identify the TMMs. The same procedure is applied to other 34 stations and the results are listed in Table 5. Moreover, the monthly mean solar radiation data and monthly mean wind speed acquired from TMYs data for 35 stations are given in Tables A1 and A2, respectively.

Also, Table 6 shows the selected times of each year for 12 TMMs in total. It is clear that 2008 is the most frequent year while the least frequent year is 2012, which is selected eight times altogether. 
Table 4. ERMSD of the three candidate years for each month in Lhasa (the bold number shows the lowest ERMSD value in the month).

\begin{tabular}{|c|c|c|c|c|}
\hline Month & Method & TMY_D & TMY_F & TMY_M \\
\hline \multirow{2}{*}{ Jan. } & Year & 1998 & 1994 & 2001 \\
\hline & ERMSD & 0.286 & 0.313 & 0.293 \\
\hline \multirow{2}{*}{ Feb. } & Year & 2010 & 2007 & 1999 \\
\hline & ERMSD & 0.330 & 0.331 & 0.350 \\
\hline \multirow{2}{*}{ Mar. } & Year & 2005 & 2008 & 2009 \\
\hline & ERMSD & 0.328 & 0.297 & 0.380 \\
\hline \multirow{2}{*}{ Apr. } & Year & 2005 & 2008 & 2008 \\
\hline & ERMSD & 0.410 & 0.360 & 0.390 \\
\hline \multirow{2}{*}{ May } & Year & 2010 & 2011 & 1994 \\
\hline & ERMSD & 0.351 & 0.394 & 0.453 \\
\hline \multirow{2}{*}{ Jun. } & Year & 1997 & 2006 & 1994 \\
\hline & ERMSD & 0.397 & 0.334 & 0.350 \\
\hline \multirow{2}{*}{ Jul. } & Year & 1999 & 1999 & 2014 \\
\hline & ERMSD & 0.327 & 0.322 & 0.329 \\
\hline \multirow{2}{*}{ Aug. } & Year & 2001 & 2010 & 2014 \\
\hline & ERMSD & 0.310 & 0.340 & 0.297 \\
\hline \multirow{2}{*}{ Sep. } & Year & 2006 & 2001 & 2001 \\
\hline & ERMSD & 0.331 & 0.219 & 0.247 \\
\hline \multirow{2}{*}{ Oct. } & Year & 1999 & 2010 & 2000 \\
\hline & ERMSD & 0.366 & 0.283 & 0.299 \\
\hline \multirow{2}{*}{ Nov. } & Year & 1998 & 1999 & 2012 \\
\hline & ERMSD & 0.291 & 0.239 & 0.293 \\
\hline \multirow[b]{2}{*}{ Dec. } & Year & 2003 & 2000 & 2001 \\
\hline & ERMSD & 0.273 & 0.253 & 0.259 \\
\hline
\end{tabular}

Table 5. The TMYs for the hybrid method of 35 cities in six different climatic zones of China.

\begin{tabular}{|c|c|c|c|c|c|c|c|c|c|c|c|c|c|}
\hline \multirow{2}{*}{ Climates } & \multirow{2}{*}{ Station } & \multicolumn{12}{|c|}{ Month } \\
\hline & & Jan. & Feb. & Mar. & Apr. & May & Jun. & Jul. & Aug. & Sep. & Oct. & Nov. & Dec. \\
\hline $\mathrm{TZ}$ & Haikou & 1996 & 2006 & 1997 & 1998 & 2004 & 2003 & 2000 & 1999 & 2001 & 1996 & 1996 & 2015 \\
\hline $\mathrm{TZ}$ & Sanya & 2002 & 2002 & 2002 & 2002 & 1996 & 2003 & 2004 & 1994 & 2000 & 1999 & 2003 & 2004 \\
\hline SZ & Changsha & 2004 & 1997 & 2015 & 2014 & 2012 & 2003 & 2008 & 1995 & 2004 & 2012 & 1999 & 2006 \\
\hline SZ & Chengdu & 1994 & 1998 & 1995 & 2003 & 2002 & 1998 & 2000 & 1995 & 2003 & 1999 & 2001 & 1994 \\
\hline SZ & Fuzhou & 2007 & 2015 & 1995 & 2008 & 2002 & 1994 & 1998 & 2008 & 2007 & 2001 & 2004 & 2006 \\
\hline SZ & Guangzhou & 2007 & 2002 & 2003 & 1997 & 2010 & 2002 & 2008 & 2001 & 2004 & 1999 & 1999 & 1996 \\
\hline SZ & Guiyang & 2006 & 2002 & 2005 & 2005 & 2012 & 2007 & 2009 & 2007 & 2006 & 2010 & 2004 & 2010 \\
\hline SZ & Hangzhou & 1995 & 2003 & 2015 & 1997 & 2015 & 2014 & 2011 & 2011 & 2008 & 2008 & 2010 & 2006 \\
\hline SZ & Hefei & 1995 & 2003 & 2015 & 1997 & 2015 & 2014 & 2011 & 2011 & 2008 & 2008 & 2010 & 2006 \\
\hline SZ & Kunming & 1998 & 2015 & 2001 & 2002 & 2013 & 2004 & 2014 & 2008 & 2008 & 2006 & 2000 & 2000 \\
\hline SZ & Nanchang & 2004 & 1995 & 2014 & 2014 & 1998 & 2007 & 2008 & 2008 & 2009 & 2015 & 1999 & 2006 \\
\hline $\mathrm{SZ}$ & Nanjing & 2013 & 1997 & 1994 & 2000 & 2000 & 2007 & 2002 & 1996 & 2007 & 2005 & 1996 & 2013 \\
\hline SZ & Nanning & 2007 & 2011 & 2005 & 2008 & 2002 & 2014 & 2008 & 2012 & 2012 & 2014 & 2013 & 2010 \\
\hline SZ & Shanghai & 1994 & 2011 & 1995 & 2000 & 2004 & 2003 & 2010 & 2005 & 2013 & 2013 & 2014 & 2011 \\
\hline SZ & Wuhan & 2006 & 1997 & 2006 & 2001 & 2005 & 2014 & 2004 & 1995 & 2007 & 2008 & 1997 & 2006 \\
\hline WTZ & Beijing & 2005 & 2015 & 2004 & 1997 & 2000 & 2006 & 2008 & 2011 & 2000 & 2013 & 2004 & 2000 \\
\hline WTZ & Jinan & 2005 & 2015 & 2008 & 2009 & 2015 & 2010 & 2010 & 2001 & 1996 & 2005 & 2007 & 2006 \\
\hline WTZ & Kashgar & 2005 & 2013 & 2005 & 2010 & 2011 & 2006 & 2008 & 2003 & 2006 & 2008 & 1999 & 2006 \\
\hline WTZ & Lanzhou & 2000 & 1994 & 2000 & 2000 & 1999 & 2001 & 2002 & 2000 & 1996 & 1998 & 1997 & 2003 \\
\hline WTZ & Taiyuan & 2007 & 1995 & 2008 & 2009 & 2005 & 2006 & 2002 & 2011 & 2000 & 2008 & 2001 & 2006 \\
\hline WTZ & Tianjin & 2005 & 2011 & 2009 & 2004 & 2003 & 2007 & 2005 & 2002 & 2005 & 2012 & 2004 & 1996 \\
\hline WTZ & Xian & 1995 & 2001 & 1995 & 1995 & 1997 & 2002 & 2000 & 1999 & 1999 & 2001 & 2004 & 1997 \\
\hline WTZ & Zhengzhou & 1997 & 1997 & 2015 & 2007 & 2010 & 2001 & 2009 & 2002 & 2000 & 2008 & 1998 & 2006 \\
\hline MTZ & Changchun & 2004 & 1997 & 2006 & 2011 & 2013 & 2011 & 2002 & 2005 & 2006 & 2006 & 2006 & 1995 \\
\hline MTZ & Dongsheng & 1997 & 2011 & 2000 & 2000 & 1996 & 2006 & 2004 & 2013 & 2011 & 2008 & 2002 & 1999 \\
\hline MTZ & Hami & 2008 & 2015 & 2009 & 1997 & 2009 & 2006 & 2014 & 2006 & 2008 & 2006 & 2011 & 2006 \\
\hline MTZ & Harbin & 2003 & 1994 & 2009 & 2004 & 2001 & 1995 & 2008 & 2005 & 2004 & 2008 & 2001 & 1996 \\
\hline MTZ & Jiamusi & 2005 & 2013 & 2000 & 2001 & 2003 & 2015 & 2010 & 1995 & 2002 & 2008 & 2008 & 1994 \\
\hline MTZ & Shenyang & 2009 & 2003 & 2009 & 2000 & 2007 & 2013 & 2005 & 2008 & 2006 & 2006 & 2004 & 2003 \\
\hline MTZ & Urumqi & 2012 & 2009 & 2006 & 2009 & 2005 & 2014 & 1994 & 2004 & 2013 & 2008 & 2005 & 2011 \\
\hline MTZ & Yinchuan & 2007 & 2003 & 2012 & 2003 & 2008 & 2003 & 2007 & 2008 & 2000 & 2010 & 1999 & 2003 \\
\hline CTZ & Mohe & 2003 & 2004 & 2006 & 2003 & 2005 & 2002 & 2002 & 2007 & 2003 & 2003 & 2005 & 2001 \\
\hline TPZ & Lhasa & 1998 & 2010 & 2008 & 2008 & 2010 & 2006 & 1999 & 2014 & 2001 & 2010 & 1999 & 2000 \\
\hline $\mathrm{TPZ}$ & Nagqu & 2010 & 2007 & 2003 & 2003 & 2015 & 2009 & 1998 & 2009 & 2008 & 2000 & 2001 & 2013 \\
\hline TPZ & Xining & 2013 & 2001 & 2000 & 2000 & 2013 & 2010 & 2007 & 2008 & 2003 & 2008 & 1995 & 2006 \\
\hline
\end{tabular}


Table 6. The year selection frequency of each month to be a TMM in the period of 1994-2015.

\begin{tabular}{cccccccccccccc}
\hline Year & Jan. & Feb. & Mar. & Apr. & May & Jun. & Jul. & Aug. & Sep. & Oct. & Nov. & Dec. & Total Times \\
\hline 1994 & 2 & 2 & 1 & 0 & 0 & 1 & 1 & 1 & 0 & 0 & 0 & 2 & 10 \\
1995 & 3 & 2 & 4 & 1 & 0 & 1 & 0 & 4 & 0 & 0 & 1 & 1 & 17 \\
1996 & 1 & 0 & 0 & 0 & 2 & 0 & 0 & 1 & 2 & 1 & 2 & 3 & 12 \\
1997 & 2 & 5 & 1 & 5 & 1 & 0 & 0 & 0 & 0 & 0 & 2 & 1 & 17 \\
1998 & 2 & 1 & 0 & 1 & 1 & 1 & 2 & 0 & 0 & 1 & 1 & 0 & 10 \\
1999 & 0 & 0 & 0 & 0 & 1 & 0 & 1 & 2 & 1 & 3 & 6 & 1 & 15 \\
2000 & 1 & 0 & 4 & 6 & 2 & 0 & 3 & 1 & 5 & 1 & 1 & 3 & 27 \\
2001 & 0 & 2 & 1 & 2 & 1 & 2 & 0 & 2 & 2 & 2 & 4 & 1 & 19 \\
2002 & 1 & 3 & 1 & 2 & 3 & 3 & 5 & 2 & 1 & 0 & 1 & 0 & 22 \\
2003 & 2 & 4 & 2 & 4 & 2 & 5 & 0 & 1 & 3 & 1 & 1 & 3 & 28 \\
2004 & 3 & 1 & 1 & 2 & 2 & 1 & 3 & 1 & 3 & 0 & 6 & 1 & 24 \\
2005 & 5 & 0 & 3 & 1 & 4 & 0 & 2 & 3 & 1 & 2 & 2 & 0 & 23 \\
2006 & 2 & 1 & 4 & 0 & 0 & 6 & 0 & 1 & 4 & 4 & 1 & 12 & 35 \\
2007 & 5 & 1 & 0 & 1 & 1 & 4 & 2 & 2 & 3 & 0 & 1 & 0 & 20 \\
2008 & 1 & 0 & 3 & 3 & 1 & 0 & 7 & 6 & 5 & 11 & 1 & 0 & 38 \\
2009 & 1 & 1 & 4 & 3 & 1 & 1 & 2 & 1 & 1 & 0 & 0 & 0 & 15 \\
2010 & 1 & 1 & 0 & 1 & 3 & 2 & 3 & 0 & 0 & 3 & 2 & 2 & 18 \\
2011 & 0 & 4 & 0 & 1 & 1 & 1 & 2 & 4 & 1 & 0 & 1 & 2 & 17 \\
2012 & 1 & 0 & 1 & 0 & 2 & 0 & 0 & 1 & 1 & 2 & 0 & 0 & 8 \\
2013 & 2 & 2 & 0 & 0 & 3 & 1 & 0 & 1 & 2 & 2 & 1 & 2 & 16 \\
2014 & 0 & 0 & 1 & 2 & 0 & 5 & 2 & 1 & 0 & 1 & 1 & 0 & 13 \\
2015 & 0 & 5 & 4 & 0 & 4 & 1 & 0 & 0 & 0 & 1 & 0 & 1 & 16 \\
\hline
\end{tabular}

According to the summary, it can be concluded that 2008 follows long-term weather patterns more closely than the others over the period of 1994-2015. Moreover, for different months the times may vary for the same year, and 12 and 0 are the largest and lowest numbers, respectively. That is to say, a particular month is selected for no more than 12 cities among the selected stations.

Monthly solar radiation data gained from TMY_D, TMY_F, TMY_M, and the proposed hybrid method are compared with the long-term monthly mean measured data for Haikou (TZ), Shanghai (SZ), Zhengzhou (WTZ), Yinchuan (MTZ), Mohe (CTZ) and Lhasa (TPZ), shown separately in Figure 6.

It can be clearly seen that the solar radiation data obtained from the four methods all agree well with the measured data during the period 1994-2015. Moreover, the hybrid method performs better than other three methods especially for the four stations, Zhengzhou (WTZ), Yinchuan (MTZ), Mohe (CTZ) and Lhasa (TPZ). Additionally, the prediction of monthly mean solar radiation is researched in the paper. The excellence and distinctive features of Gaussian Process Regression (GPR) forecasting model include its output probability distribution characteristic and capabilities to adaptively obtain the hyper-parameters in the model $[43,44]$. In this part, the GPR model is recommended to forecast the monthly mean solar radiation by year 2016 using the last 22 years historical data. The selection of input variables includes solar radiation, dry-bulb temperature, relative humidity and wind speed in the last four years.

In order to test the forecasting performance of the GPR model, a simulation is carried out to forecast the monthly solar radiation in 2015. The index analysis of interval forecasting results under the $90 \%$ confidence level is shown in Table 7 . It can be concluded that most of actual monthly mean solar radiation is within the confidence interval, and the forecasting results can well track the change of solar radiation from the view of MAPE values. The smaller the MAPE, the better the forecasting accuracy, which illustrates that the predictive value is closer to actual result. The best forecasting results are obtained in Lhasa and the interval width is narrower with the increasing forecasting accuracy. Besides, the FICP reduces due to the narrower interval width of smaller FIAW. The monthly mean solar radiation forecasting results by 2016 in different climates of China are shown in Table A3. It can be seen from the table that the predicted results have high similarities with historical data which indicates stable solar radiation change rules in these areas. In conclusion, the GPR forecasting model can directly generate the monthly mean solar radiation interval forecasting result rather than deterministic point 
value which reflects the uncertain change of future solar radiation. Further, the interval forecasting results can give more guiding significance for actual application related to energy areas.

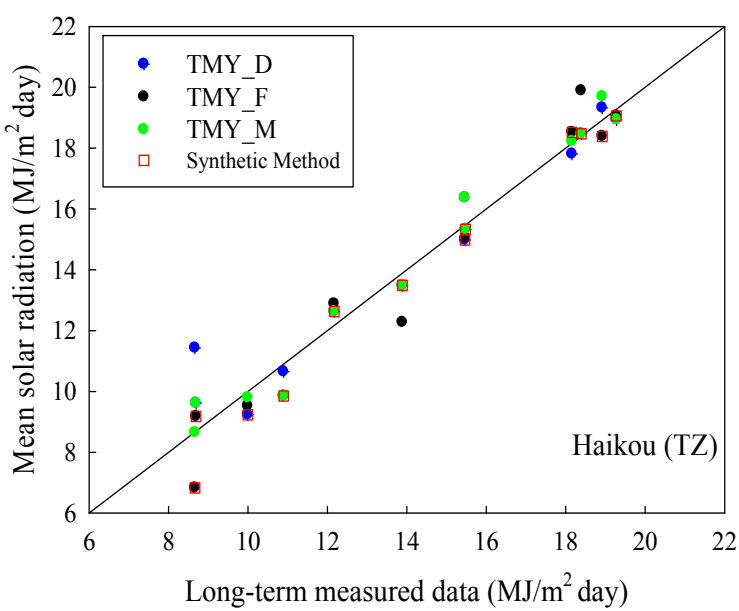

(a)

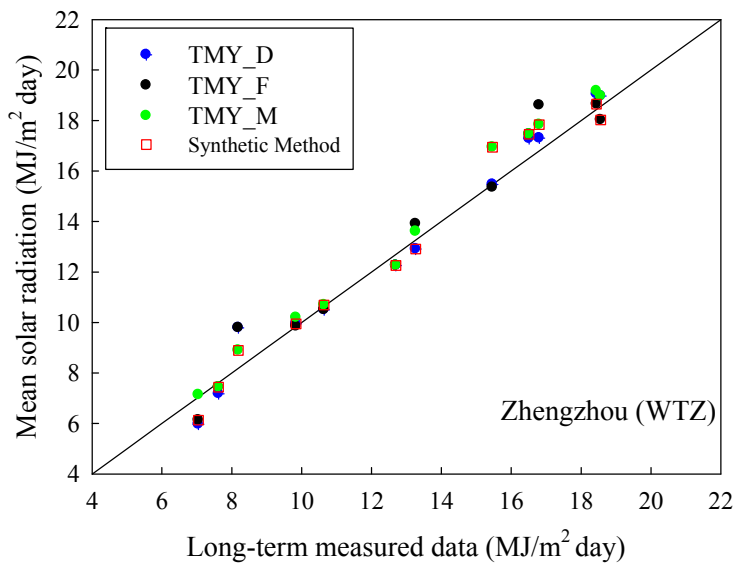

(c)

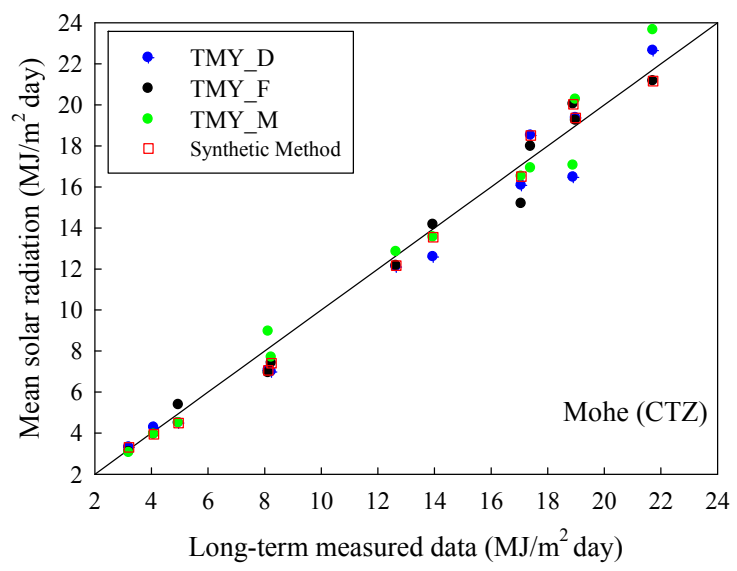

(e)

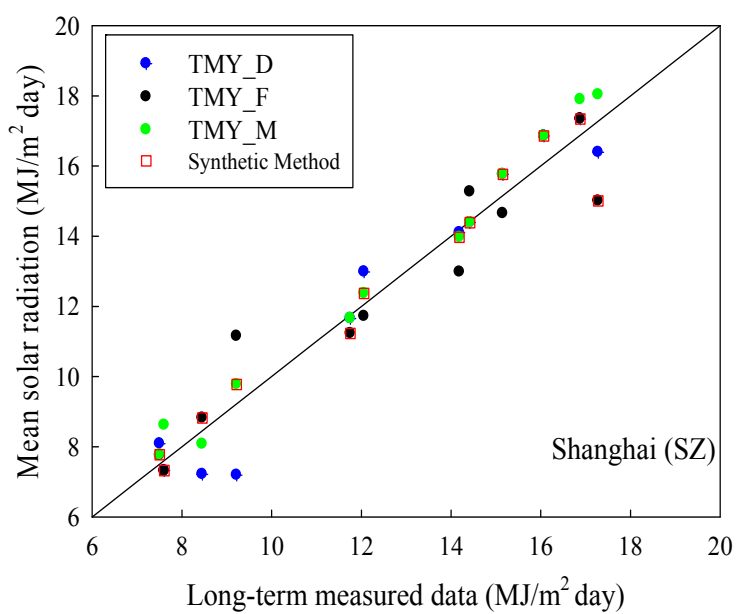

(b)

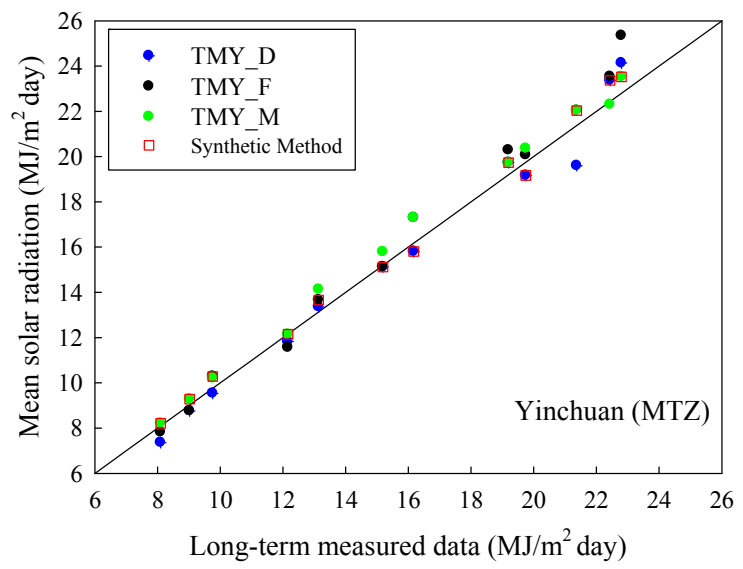

(d)

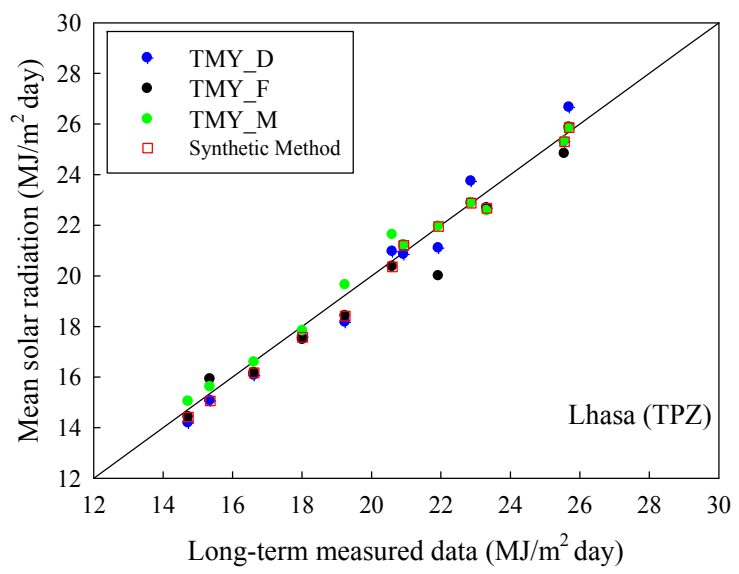

(f)

Figure 6. Comparing the long-term measured monthly mean solar radiation and the monthly mean solar radiation from TMYs using TMY_D, TMY_F, TMY_M and hybrid method for six typical climatic zones of China, at (a) Haikou; (b) Shanghai; (c) Zhengzhou; (d) Yinchuan; (f) Lhasa stations (1994-2015 measured data); and (e) Mohe station (1997-2007 measured data). 
Table 7. The index results of monthly mean solar radiation forecasting for 2015 in different climates of China.

\begin{tabular}{ccccc}
\hline Stations & MAPE (\%) [45] & RMSE (MJ/m $\mathbf{~}^{\mathbf{2}}$ [45] & FICP (\%) [46] & FIAW [46] \\
\hline Haikou (TZ) & 11.03 & 1.9919 & 91.67 & 0.5153 \\
Shanghai (SZ) & 10.75 & 1.3626 & 100 & 0.6256 \\
Zhengzhou (WTZ) & 13.47 & 1.6059 & 91.67 & 0.5199 \\
Yinchuan (MTZ) & 9.77 & 1.5892 & 91.67 & 0.3812 \\
Lhasa (TPZ) & 7.27 & 1.5325 & 83.33 & 0.2124 \\
\hline
\end{tabular}

\section{Conclusions}

The generation of the TMY data is essential and important for solar energy utilization. In this paper, the performance of four TMY generation methods: the Danish method, the Festa-Ratto method, the Modified Typical Meteorological Year Method and the hybrid method are compared. These methods are used to generate and investigate TMYs for 35 stations in six different climatic zones of China using at least 10 years measured weather data, including air dry-bulb temperature, relative humidity, wind speed, pressure, sunshine duration and global solar radiation. Taking Lhasa as an example, the process of the hybrid method are presented and analyzed in this study. The monthly mean solar radiation data and monthly mean wind speed acquired from TMYs data, using the hybrid method, are appeared in the tabulation. There is a good agreement between the typical solar radiation data and the long-term measured data for the hybrid method on a monthly basis. Moreover, the proposed GPR model has good performance for forecasting monthly mean solar radiation. It is believed that the TMY data will have good impact on the related scientific research. Future work will focus on the in-depth long-term prediction of the climatology for different areas in China. We hope to report these findings in the near future.

Acknowledgments: The research is supported by National Natural Science Foundation of China (Program No. 51507052), the China Postdoctoral Science Foundation (Program No. 2015M571653), the 111 Project (B14022), and the Fundamental Research Funds for the Central Universities (Program No. 2015B02714). The authors also thank the China Meteorological Administration.

Author Contributions: Haixiang Zang is the principal investigator of this work. He performed the simulations and wrote the manuscript; Miaomiao Wang and Jing Huang contributed to the data analysis work and language editing; Zhinong Wei and Guoqiang Sun designed the simulations solution and checked the whole manuscript. All authors revised and approved the publication.

Conflicts of Interest: The authors declare no conflict of interest. 


\section{Appendix A}

Table A1. Summary of monthly mean solar radiation data of 35 cities in six different climatic zones of China from the TMYs using the synthetic method.

\begin{tabular}{|c|c|c|c|c|c|c|c|c|c|c|c|c|c|}
\hline \multirow{2}{*}{ Climates } & \multirow{2}{*}{ Station } & \multicolumn{12}{|c|}{ Month } \\
\hline & & Jan. & Feb. & Mar. & Apr. & May & Jun. & Jul. & Aug. & Sep. & Oct. & Nov. & Dec. \\
\hline $\mathrm{TZ}$ & Haikou & 9.177 & 9.231 & 12.628 & 15.330 & 18.470 & 18.386 & 19.059 & 18.518 & 14.981 & 13.484 & 9.852 & 6.826 \\
\hline $\mathrm{TZ}$ & Sanya & 14.055 & 15.278 & 16.459 & 21.555 & 20.720 & 18.314 & 17.675 & 19.706 & 18.060 & 14.590 & 14.721 & 12.576 \\
\hline SZ & Changsha & 4.139 & 5.724 & 7.265 & 10.369 & 11.314 & 14.570 & 18.974 & 19.259 & 12.416 & 9.254 & 8.574 & 5.993 \\
\hline SZ & Chengdu & 5.146 & 4.491 & 8.851 & 11.301 & 12.995 & 12.602 & 12.495 & 13.814 & 7.931 & 5.589 & 5.369 & 3.435 \\
\hline SZ & Fuzhou & 7.466 & 9.497 & 9.504 & 12.403 & 14.187 & 16.131 & 18.320 & 18.166 & 12.802 & 13.044 & 9.449 & 7.504 \\
\hline SZ & Guangzhou & 9.995 & 10.471 & 8.118 & 9.360 & 10.872 & 14.429 & 15.315 & 15.015 & 15.371 & 13.545 & 11.965 & 10.598 \\
\hline SZ & Guiyang & 5.208 & 5.983 & 8.138 & 13.836 & 11.995 & 12.296 & 14.874 & 16.986 & 14.133 & 10.050 & 6.989 & 6.917 \\
\hline SZ & Hangzhou & 9.608 & 8.566 & 11.257 & 13.431 & 15.240 & 14.203 & 18.066 & 14.778 & 12.344 & 9.885 & 8.348 & 7.843 \\
\hline SZ & Hefei & 8.120 & 8.464 & 12.997 & 17.106 & 17.435 & 16.782 & 17.734 & 16.202 & 12.148 & 10.404 & 9.107 & 6.954 \\
\hline SZ & Kunming & 15.034 & 18.440 & 18.423 & 20.271 & 19.387 & 14.843 & 16.457 & 13.782 & 14.314 & 12.719 & 14.342 & 12.086 \\
\hline SZ & Nanchang & 5.765 & 8.584 & 9.360 & 12.010 & 15.703 & 14.821 & 20.261 & 16.786 & 15.273 & 12.404 & 9.694 & 7.960 \\
\hline SZ & Nanjing & 8.368 & 9.531 & 12.477 & 16.325 & 17.168 & 14.333 & 19.253 & 16.040 & 12.273 & 12.104 & 6.453 & 7.811 \\
\hline SZ & Nanning & 8.246 & 7.898 & 7.656 & 12.272 & 14.841 & 15.148 & 17.001 & 17.474 & 16.166 & 14.993 & 11.274 & 8.674 \\
\hline SZ & Shanghai & 7.321 & 9.778 & 12.373 & 15.763 & 17.342 & 13.972 & 15.006 & 16.856 & 14.387 & 11.231 & 8.821 & 7.773 \\
\hline SZ & Wuhan & 5.922 & 8.048 & 12.245 & 14.108 & 14.604 & 14.251 & 17.768 & 15.667 & 14.179 & 10.413 & 7.578 & 7.176 \\
\hline WTZ & Beijing & 8.536 & 10.489 & 14.559 & 18.707 & 21.316 & 17.732 & 17.279 & 17.128 & 14.939 & 11.255 & 8.643 & 6.707 \\
\hline WTZ & Jinan & 8.208 & 10.385 & 14.578 & 18.077 & 18.943 & 18.317 & 16.494 & 15.346 & 14.300 & 11.401 & 8.797 & 6.783 \\
\hline WTZ & Kashgar & 7.329 & 10.388 & 12.489 & 18.224 & 23.711 & 26.325 & 24.731 & 21.653 & 15.905 & 13.923 & 8.155 & 6.098 \\
\hline WTZ & Lanzhou & 7.921 & 10.664 & 14.536 & 17.873 & 19.168 & 19.910 & 20.832 & 18.297 & 15.987 & 10.614 & 8.160 & 7.023 \\
\hline WTZ & Taiyuan & 7.358 & 11.339 & 13.841 & 18.930 & 20.140 & 18.322 & 19.063 & 16.732 & 14.539 & 11.709 & 8.813 & 6.090 \\
\hline WTZ & Tianjin & 7.451 & 10.103 & 14.896 & 17.916 & 18.830 & 16.502 & 17.447 & 17.625 & 13.020 & 11.334 & 8.104 & 6.406 \\
\hline WTZ & Xian & 7.727 & 8.117 & 13.105 & 15.641 & 18.433 & 17.651 & 17.908 & 18.632 & 12.142 & 6.944 & 7.149 & 5.087 \\
\hline WTZ & Zhengzhou & 7.436 & 9.947 & 12.907 & 17.456 & 18.023 & 18.648 & 17.835 & 16.941 & 12.256 & 10.692 & 8.897 & 6.129 \\
\hline MTZ & Changchun & 6.817 & 10.962 & 14.136 & 17.933 & 21.114 & 20.140 & 19.448 & 14.707 & 15.687 & 11.256 & 7.667 & 5.784 \\
\hline MTZ & Dongsheng & 9.657 & 11.450 & 16.749 & 19.914 & 24.373 & 23.592 & 22.361 & 20.068 & 15.216 & 13.717 & 10.045 & 8.349 \\
\hline MTZ & Hami & 7.738 & 11.036 & 16.181 & 22.887 & 25.072 & 26.175 & 24.427 & 21.980 & 17.514 & 12.980 & 7.664 & 6.700 \\
\hline MTZ & Harbin & 5.589 & 9.381 & 13.535 & 16.980 & 19.872 & 21.614 & 17.579 & 15.910 & 14.545 & 9.690 & 6.717 & 4.651 \\
\hline MTZ & Jiamusi & 5.465 & 9.658 & 12.025 & 16.210 & 18.045 & 20.722 & 18.044 & 17.465 & 13.473 & 9.458 & 5.958 & 4.711 \\
\hline MTZ & Shenyang & 6.982 & 9.788 & 14.603 & 16.557 & 20.265 & 20.131 & 17.108 & 17.280 & 15.450 & 11.165 & 6.243 & 6.307 \\
\hline MTZ & Urumqi & 5.909 & 7.156 & 13.301 & 18.448 & 22.087 & 23.989 & 23.226 & 20.243 & 17.687 & 11.529 & 5.974 & 3.926 \\
\hline MTZ & Yinchuan & 9.285 & 12.145 & 15.802 & 19.165 & 23.365 & 23.526 & 22.035 & 19.730 & 15.120 & 13.658 & 10.284 & 8.207 \\
\hline CTZ & Mohe & 3.941 & 7.055 & 13.544 & 16.511 & 20.027 & 21.158 & 19.364 & 18.506 & 12.161 & 7.410 & 4.492 & 3.307 \\
\hline TPZ & Lhasa & 15.057 & 17.569 & 20.352 & 22.874 & 25.299 & 25.862 & 22.668 & 21.951 & 21.205 & 18.407 & 16.164 & 14.415 \\
\hline TPZ & Nagqu & 14.408 & 14.884 & 19.939 & 22.281 & 21.559 & 24.003 & 21.835 & 21.291 & 18.503 & 18.451 & 17.801 & 14.235 \\
\hline $\mathrm{TPZ}$ & Xining & 10.700 & 12.703 & 16.434 & 20.058 & 20.161 & 21.389 & 20.452 & 20.352 & 16.429 & 13.258 & 10.886 & 8.845 \\
\hline
\end{tabular}


Table A2. Summary of monthly mean wind speed of 35 cities in six different climatic zones of China from the TMYs using the synthetic method.

\begin{tabular}{|c|c|c|c|c|c|c|c|c|c|c|c|c|c|}
\hline \multirow{2}{*}{ Climates } & \multirow{2}{*}{ Station } & \multicolumn{12}{|c|}{ Month } \\
\hline & & Jan. & Feb. & Mar. & Apr. & May & Jun. & Jul. & Aug. & Sep. & Oct. & Nov. & Dec. \\
\hline $\mathrm{TZ}$ & Haikou & 2.1742 & 1.7857 & 1.8129 & 2.2500 & 1.8065 & 2.0100 & 1.8000 & 1.7194 & 1.5367 & 2.2161 & 2.3200 & 3.1839 \\
\hline $\mathrm{TZ}$ & Sanya & 1.7387 & 1.8786 & 1.4032 & 1.4633 & 1.7839 & 1.8767 & 1.5097 & 1.2323 & 1.7767 & 2.0677 & 1.9233 & 1.8032 \\
\hline SZ & Changsha & 2.1065 & 2.1179 & 2.4903 & 1.8500 & 1.8839 & 1.9400 & 2.2677 & 2.6258 & 2.0733 & 2.0774 & 2.1733 & 2.0097 \\
\hline SZ & Chengdu & 0.8871 & 1.0643 & 1.3742 & 1.9067 & 1.7774 & 1.8667 & 1.3161 & 1.1871 & 1.5833 & 0.9032 & 1.0133 & 0.8774 \\
\hline SZ & Fuzhou & 2.2968 & 1.9607 & 2.3871 & 2.2700 & 2.5677 & 2.9467 & 2.9484 & 2.5710 & 2.7867 & 2.6548 & 2.5067 & 2.4032 \\
\hline SZ & Guangzhou & 1.5935 & 1.4250 & 1.8935 & 1.7500 & 1.5258 & 1.8833 & 1.5774 & 1.3742 & 1.2733 & 1.6484 & 1.6067 & 1.5903 \\
\hline SZ & Guiyang & 2.6161 & 3.1107 & 2.6613 & 2.7433 & 2.6258 & 2.2467 & 2.4903 & 2.2000 & 2.3533 & 2.3871 & 2.3733 & 2.2161 \\
\hline SZ & Hangzhou & 1.9194 & 2.0500 & 1.9968 & 2.2600 & 2.2484 & 1.9367 & 2.0065 & 2.0871 & 2.2433 & 1.5645 & 1.6733 & 1.7806 \\
\hline SZ & Hefei & 2.8097 & 2.6750 & 3.0871 & 2.6433 & 2.4226 & 2.1233 & 2.7484 & 2.6161 & 2.3200 & 2.0984 & 2.4767 & 1.9323 \\
\hline SZ & Kunming & 2.1194 & 2.9464 & 2.1258 & 2.4067 & 2.8000 & 1.8433 & 2.0258 & 2.1065 & 2.0467 & 2.1323 & 1.3700 & 1.3968 \\
\hline SZ & Nanchang & 1.8194 & 2.2357 & 1.7839 & 1.6467 & 1.8226 & 1.6133 & 2.1032 & 1.7903 & 2.2433 & 1.6839 & 1.7500 & 1.7968 \\
\hline SZ & Nanjing & 2.4161 & 1.9000 & 2.5387 & 2.2767 & 1.9581 & 2.0533 & 1.9387 & 2.2742 & 1.9167 & 1.8581 & 2.3733 & 2.0548 \\
\hline SZ & Nanning & 1.5968 & 1.4214 & 1.4839 & 1.6733 & 1.3548 & 1.3967 & 1.7161 & 1.6516 & 1.4800 & 1.1355 & 1.3767 & 1.4645 \\
\hline SZ & Shanghai & 2.5968 & 2.5286 & 2.9806 & 3.1467 & 3.2774 & 2.5467 & 2.9774 & 3.9871 & 2.7167 & 2.9097 & 2.3567 & 2.7355 \\
\hline SZ & Wuhan & 1.3516 & 0.9536 & 1.2677 & 1.2900 & 1.3194 & 1.2933 & 1.1129 & 1.6258 & 1.4833 & 1.0548 & 0.8900 & 1.1871 \\
\hline WTZ & Beijing & 2.4516 & 2.3357 & 2.8710 & 2.8500 & 2.9387 & 2.4033 & 2.0419 & 1.9387 & 1.7767 & 1.7516 & 2.1767 & 2.2968 \\
\hline WTZ & Jinan & 3.0548 & 2.0821 & 3.2710 & 3.2000 & 2.7065 & 2.5433 & 2.0806 & 2.7774 & 2.5667 & 2.9710 & 2.8600 & 2.6710 \\
\hline WTZ & Kashgar & 1.3645 & 1.4857 & 1.5452 & 1.9967 & 2.0581 & 2.5667 & 2.1516 & 2.1968 & 1.5667 & 1.3645 & 1.2833 & 1.1774 \\
\hline WTZ & Lanzhou & 0.4323 & 0.5536 & 0.7839 & 1.0100 & 1.2065 & 1.3367 & 1.4516 & 0.8548 & 1.0900 & 0.4516 & 0.4967 & 0.2065 \\
\hline WTZ & Taiyuan & 1.7323 & 2.1607 & 2.2194 & 2.0533 & 2.7419 & 2.0400 & 1.0161 & 1.2806 & 1.1667 & 1.4290 & 1.7967 & 1.6645 \\
\hline WTZ & Tianjin & 2.3742 & 2.4500 & 2.9548 & 3.3067 & 2.4355 & 2.2933 & 2.1484 & 1.7613 & 1.8133 & 2.4387 & 2.3567 & 2.1903 \\
\hline WTZ & Xian & 1.5226 & 0.9429 & 1.9903 & 1.9767 & 2.0677 & 1.0733 & 1.5484 & 1.9968 & 1.4967 & 0.7484 & 1.1533 & 1.2710 \\
\hline WTZ & Zhengzhou & 2.1871 & 2.0786 & 2.0839 & 2.3433 & 2.4161 & 2.3567 & 2.0774 & 2.1387 & 1.7800 & 1.5871 & 1.8833 & 1.8774 \\
\hline MTZ & Changchun & 2.8387 & 3.3500 & 3.9935 & 3.8067 & 3.5806 & 3.0867 & 2.7516 & 2.3387 & 2.5867 & 2.9645 & 3.4633 & 2.8710 \\
\hline MTZ & Dongsheng & 2.3290 & 2.5143 & 2.7065 & 3.8667 & 3.5129 & 2.8767 & 2.5097 & 2.6677 & 2.3867 & 2.5194 & 2.8033 & 3.1355 \\
\hline MTZ & Hami & 1.3871 & 1.3000 & 1.7387 & 1.3400 & 1.5871 & 1.2800 & 1.2516 & 1.2774 & 1.0367 & 1.0484 & 1.1833 & 1.2903 \\
\hline MTZ & Harbin & 2.5194 & 2.1321 & 2.4645 & 2.9467 & 3.3677 & 3.1600 & 1.9097 & 1.8226 & 2.4533 & 2.1387 & 3.0100 & 2.5839 \\
\hline MTZ & Jiamusi & 1.9323 & 2.5750 & 3.5903 & 3.1267 & 3.2903 & 2.3900 & 2.1194 & 2.7161 & 2.3133 & 2.8452 & 2.9833 & 2.8000 \\
\hline MTZ & Shenyang & 2.0032 & 2.6143 & 2.8161 & 3.4500 & 2.7903 & 2.3867 & 2.3000 & 1.8032 & 2.2067 & 2.7226 & 2.4600 & 2.4484 \\
\hline MTZ & Urumgi & 1.5355 & 1.6714 & 2.0839 & 2.9467 & 2.6290 & 2.4300 & 2.4968 & 2.4742 & 2.3433 & 2.1161 & 1.8033 & 1.6000 \\
\hline MTZ & Yinchuan & 1.7935 & 2.1071 & 2.1484 & 3.4600 & 2.1968 & 2.8400 & 1.8548 & 1.7097 & 1.9967 & 1.4452 & 2.0300 & 2.0613 \\
\hline $\mathrm{CTZ}$ & Mohe & 0.6161 & 0.6966 & 2.1129 & 2.5967 & 2.5806 & 2.0267 & 1.6194 & 1.7000 & 1.8933 & 2.2839 & 1.4733 & 1.1194 \\
\hline TPZ & Lhasa & 2.1516 & 1.4821 & 1.8452 & 1.7967 & 2.1871 & 1.9800 & 1.7226 & 1.8484 & 1.5800 & 1.4032 & 1.0700 & 1.3452 \\
\hline TPZ & Nagqu & 1.6258 & 2.3429 & 3.1226 & 3.0767 & 2.6194 & 2.2567 & 2.0613 & 1.9032 & 1.7100 & 2.2968 & 1.5333 & 2.1677 \\
\hline TPZ & Xining & 0.8516 & 0.8857 & 1.0258 & 1.3833 & 1.1742 & 1.0767 & 0.8613 & 0.9290 & 0.7867 & 0.7839 & 0.6900 & 0.7484 \\
\hline
\end{tabular}


Table A3. The monthly mean solar radiation interval forecasting by 2016 in different climates of China.

\begin{tabular}{|c|c|c|c|c|c|c|}
\hline Month & Station & $90 \%$ Confidence Level & Forecasting Mean Results & Station & $90 \%$ Confidence Level & Forecasting Mean Results \\
\hline Jan. & & {$[5.28,12.46]$} & 8.87 & & {$[4.47,11.19]$} & 7.83 \\
\hline Feb. & & {$[6.92,14.07]$} & 10.49 & & {$[3.74,10.50]$} & 7.12 \\
\hline Mar. & & {$[8.95,15.71]$} & 12.33 & & {$[8.78,15.47]$} & 12.13 \\
\hline Apr. & & {$[12.66,19.39]$} & 16.03 & & {$[12.50,19.32]$} & 15.91 \\
\hline May & & {$[16.88,23.73]$} & 20.30 & & {$[12.81,19.49]$} & 16.15 \\
\hline Jun. & Haikou & {$[16.29,23.28]$} & 19.79 & Shanghai & {$[9.71,16.41]$} & 13.06 \\
\hline Jul. & (TZ) & {$[16.29,23.22]$} & 19.76 & $(\mathrm{SZ})$ & {$[13.43,20.65]$} & 17.04 \\
\hline Aug. & & {$[16.33,23.05]$} & 19.69 & & {$[12.83,19.92]$} & 16.38 \\
\hline Sep. & & {$[15.42,22.41]$} & 18.91 & & {$[10.67,17.32]$} & 13.99 \\
\hline Oct. & & {$[12.10,18.94]$} & 15.52 & & {$[9.10,15.76]$} & 12.43 \\
\hline Nov. & & {$[9.42,16.31]$} & 12.87 & & {$[5.76,12.52]$} & 9.14 \\
\hline Dec. & & {$[4.94,11.97]$} & 8.45 & & {$[4.56,11.40]$} & 7.68 \\
\hline Jan. & & {$[3.75,9.35]$} & 6.55 & & {$[6.58,11.55]$} & 9.07 \\
\hline Feb. & & {$[5.85,11.39]$} & 8.62 & & {$[9.63,14.61]$} & 12.12 \\
\hline Mar. & & {$[10.05,15.54]$} & 12.80 & & {$[14.07,18.95]$} & 16.51 \\
\hline Apr. & & {$[13.51,19.01]$} & 16.26 & & {$[17.02,21.88]$} & 19.45 \\
\hline May & & {$[15.05,20.57]$} & 17.80 & & {$[18.22,23.13]$} & 20.67 \\
\hline Jun. & Zhengzhou & {$[15.51,21.07]$} & 18.29 & Yinchuan & {$[18.30,22.18]$} & 20.74 \\
\hline Jul. & (WTZ) & {$[14.90,20.38]$} & 17.64 & (MTZ) & {$[17.69,22.58]$} & 20.14 \\
\hline Aug. & & {$[13.75,19.40]$} & 16.57 & & {$[16.55,21.37]$} & 18.96 \\
\hline Sep. & & {$[10.69,16.25]$} & 13.47 & & {$[13.04,17.88]$} & 15.46 \\
\hline Oct. & & {$[9.25,14.74]$} & 11.99 & & {$[10.92,15.82]$} & 13.37 \\
\hline Nov. & & {$[5.96,11.65]$} & 8.81 & & {$[7.02,12.09]$} & 9.56 \\
\hline Dec. & & {$[4.40,9.99]$} & 7.19 & & {$[6.29,11.26]$} & 8.77 \\
\hline Jan. & & {$[12.99,17.08]$} & 15.04 & & & \\
\hline Feb. & & {$[15.93,20.05]$} & 17.9 & & & \\
\hline Mar. & & {$[18.92,23.03]$} & 20.98 & & & \\
\hline Apr. & & {$[20.16,24.27]$} & 22.22 & & & \\
\hline May & & {$[22.62,26.79]$} & 24.71 & & & \\
\hline Jun. & Lhasa & {$[23.51,27.67]$} & 25.59 & & & \\
\hline Jul. & (TPZ) & {$[21.71,25.88]$} & 23.79 & & & \\
\hline Aug. & & {$[19.77,23.91]$} & 21.84 & & & \\
\hline Sep. & & {$[18.59,22.71]$} & 20.65 & & & \\
\hline Oct. & & {$[16.33,20.46]$} & 18.39 & & & \\
\hline Nov. & & {$[13.92,18.04]$} & 15.98 & & & \\
\hline Dec. & & {$[12.02,16.19]$} & 14.11 & & & \\
\hline
\end{tabular}




\section{References}

1. Zang, H.; Xu, Q.; Bian, H. Generation of typical solar radiation data for different climates of China. Energy 2012, 38, 236-248. [CrossRef]

2. Li, H.; Cao, F.; Bu, X.; Zhao, L. Models for calculating daily global solar radiation from air temperature in humid regions-A case study. Environ. Prog. Sustain. Energy 2015, 34, 595-599. [CrossRef]

3. Li, H.; Lo, K.; Wang, M.; Zhang, P.; Xue, L. Industrial Energy Consumption in Northeast China under the Revitalisation Strategy: A Decomposition and Policy Analysis. Energies 2016, 9, 549. [CrossRef]

4. Noorollahi, E.; Fadai, D.; Akbarpour Shirazi, M.; Ghodsipour, S. Land Suitability Analysis for Solar Farms Exploitation Using GIS and Fuzzy Analytic Hierarchy Process (FAHP)—A Case Study of Iran. Energies 2016, 9, 643. [CrossRef]

5. Corona, B.; Ruiz, D.; San Miguel, G. Life Cycle Assessment of a HYSOL Concentrated Solar Power Plant: Analyzing the Effect of Geographic Location. Energies 2016, 9, 413. [CrossRef]

6. Grantham, A.; Gel, Y.R.; Boland, J. Nonparametric short-term probabilistic forecasting for solar radiation. Sol. Energy 2016, 133, 465-475. [CrossRef]

7. Zang, H.; Xu, Q.; Du, P.; Ichiyanagi, K. A Modified Method to Generate Typical Meteorological Years from the Long-Term Weather Database. Int. J. Photoenergy 2012, 2012, 538279. [CrossRef]

8. Muñoz, J.; Perpiñán, O. A simple model for the prediction of yearly energy yields for grid-connected PV systems starting from monthly meteorological data. Renew. Energy 2016, 97, 680-688. [CrossRef]

9. Chicco, G.; Cocina, V.; Di Leo, P.; Spertino, F.; Massi Pavan, A. Error Assessment of Solar Irradiance Forecasts and AC Power from Energy Conversion Model in Grid-Connected Photovoltaic Systems. Energies 2016, 9, 8. [CrossRef]

10. Zhou, J.; Wu, Y.Z.; Yan, G. Generation of typical solar radiation year for China. Renew. Energy 2006, 31, 1972-1985. [CrossRef]

11. Yang, L.; Lam, J.C.; Liu, J.P. Analysis of typical meteorological years in different climates of China. Energy Convers. Manag. 2007, 48, 654-668. [CrossRef]

12. Skeiker, K. Generation of a typical meteorological year for Damascus zone using the Filkenstein-Schafer statistical method. Energy Convers. Manag. 2004, 45, 99-112. [CrossRef]

13. Kalogirou, S.A. Generation of typical meteorological year (TMY-2) for Nicosia, Cyprus. Renew. Energy 2003, 28, 2317-2334. [CrossRef]

14. Bre, F.; Fachinotti, V.D. Generation of typical meteorological years for the Argentine Littoral Region. Energy Build. 2016, 129, 432-444. [CrossRef]

15. Al-Azri, N.A. Development of a typical meteorological year based on dry bulb temperature and dew point for passive cooling applications. Energy Sustain. Dev. 2016, 33, 61-74. [CrossRef]

16. Rosenfelder, M.; Koppe, C.; Pfafferott, J.; Matzarakis, A. Effects of ventilation behaviour on indoor heat load based on test reference years. Int. J. Biometeorol. 2016, 60, 277-287. [CrossRef] [PubMed]

17. Handbook, A. Fundamentals Volume; American Society of Heating, Refrigerating, and Air-Conditioning Engineers, Inc.: Atlanta, GA, USA, 1989.

18. Janjai, S.; Deeyai, P. Comparison of methods for generating typical meteorological year using meteorological data from a tropical environment. Appl. Energy 2009, 86, 528-537. [CrossRef]

19. Skeiker, K. Comparison of methodologies for TMY generation using 10 years data for Damascus, Syria. Energy Convers. Manag. 2007, 48, 2090-2102. [CrossRef]

20. Ohunakin, O.S.; Adaramola, M.S.; Oyewola, O.M.; Fagbenle, R.O. Generation of a typical meteorological year for north-east, Nigeria. Appl. Energy 2013, 112, 152-159. [CrossRef]

21. Crow, L.W. Weather year for energy calculations. ASHRAE J. 1984, 26, 42-47.

22. Lund, H. The Design Reference Year User's Manual; Thermal Insulation Laboratory, Technical University of Denmark: Lyngby, Denmark, 1995.

23. Festa, R.; Ratto, C.F. Proposal of a numerical procedure to select Reference Years. Sol. Energy 1993, 50, 9-17. [CrossRef]

24. De Miguel, A.; Bilbao, J. Test reference year generation from meteorological and simulated solar radiation data. Sol. Energy 2005, 78, 695-703. [CrossRef]

25. Gazela, M.; Mathioulakis, E. A new method for typical weather data selection to evaluate long-term performance of solar energy systems. Sol. Energy 2001, 70, 339-348. [CrossRef] 
26. Pissimanis, D.; Karras, G.; Notaridou, V.; Gavra, K. The generation of a "typical meteorological year" for the city of Athens. Sol. Energy 1988, 40, 405-411. [CrossRef]

27. Fernández, M.D.; López, J.C.; Baeza, E.; Céspedes, A.; Meca, D.E.; Bailey, B. Generation and evaluation of typical meteorological year datasets for greenhouse and external conditions on the Mediterranean coast. Int. J. Biometeorol. 2015, 59, 1067-1081. [CrossRef] [PubMed]

28. Chan, A.L.S. Generation of typical meteorological years using genetic algorithm for different energy systems. Renew. Energy 2016, 90, 1-13. [CrossRef]

29. Chan, A.L.S.; Chow, T.T.; Fong, S.K.F.; Lin, J.Z. Generation of a typical meteorological year for Hong Kong. Energy Convers. Manag. 2006, 47, 87-96. [CrossRef]

30. Argiriou, A.; Lykoudis, S.; Kontoyiannidis, S.; Balaras, C.A.; Asimakopoulos, D.; Petrakis, M.; Kassomenos, P. Comparison of methodologies for tmy generation using 20 years data for Athens, Greece. Sol. Energy 1999, 66, 33-45. [CrossRef]

31. Yang, L.; Wan, K.K.W.; Li, D.H.W.; Lam, J.C. A new method to develop typical weather years in different climates for building energy use studies. Energy 2011, 36, 6121-6129. [CrossRef]

32. Zhang, Q. Development of the typical meteorological database for Chinese locations. Energy Build. 2006, 38, 1320-1326. [CrossRef]

33. Chow, T.T.; Chan, A.L.S.; Fong, K.F.; Lin, Z. Some perceptions on typical weather year-From the observations of Hong Kong and Macau. Sol. Energy 2006, 80, 459-467. [CrossRef]

34. Jiang, Y.N. Generation of typical meteorological year for different climates of China. Energy 2010, 35, 1946-1953. [CrossRef]

35. Xu, Q.; Zang, H. Comments on "Generation of typical meteorological year for different climates of China" [Energy, 35 (2010) 1946-1953]. Energy 2011, 36, 6285-6288. [CrossRef]

36. Qu, Z.; Zhou, G. Possible Impact of Climate Change on the Quality of Apples from the Major Producing Areas of China. Atmosphere 2016, 7, 113. [CrossRef]

37. Zang, H.; Guo, M.; Wei, Z.; Sun, G. Determination of the Optimal Tilt Angle of Solar Collectors for Different Climates of China. Sustainability 2016, 8, 654. [CrossRef]

38. Qing, W.; Chen, R.; Sun, W. Estimation of global radiation in China and comparison with satellite product. Environ. Earth Sci. 2013, 70, 1681-1687. [CrossRef]

39. Lund, H.; Eidorff, S. Selection Methods for Production of Test Reference Years; Thermal Insulation Laboratory, Technical University of Denmark: Lyngby, Denmark, 1981.

40. Finkelstein, J.M.; Schafer, R.E. Improved goodness-of-fit tests. Biometrika 1971, 58, 641-645. [CrossRef]

41. Pusat, S.; Ekmekçi, İ.; Akkoyunlu, M.T. Generation of typical meteorological year for different climates of Turkey. Renew. Energy 2015, 75, 144-151. [CrossRef]

42. Ohunakin, O.S.; Adaramola, M.S.; Oyewola, O.M.; Fagbenle, R.L.; Abam, F.I. A Typical Meteorological Year Generation Based on NASA Satellite Imagery (GEOS-I) for Sokoto, Nigeria. Int. J. Photoenergy 2014, 2014, 468562. [CrossRef]

43. Kumar, S.; Hegde, R.M.; Trigoni, N. Gaussian Process Regression for Fingerprinting based Localization. Ad Hoc Netw. 2016, 51, 1-10. [CrossRef]

44. Wang, Y.; Chaib-draa, B. An online Bayesian filtering framework for Gaussian process regression: Application to global surface temperature analysis. Expert Syst. Appl. 2017, 67, 285-295. [CrossRef]

45. Filik, T. Improved Spatio-Temporal Linear Models for Very Short-Term Wind Speed Forecasting. Energies 2016, 9, 168. [CrossRef]

46. Wan, C.; Xu, Z.; Pinson, P. Direct interval forecasting of wind power. IEEE Trans. Power Syst. 2013, 28, 4877-4878. [CrossRef]

(C) 2016 by the authors; licensee MDPI, Basel, Switzerland. This article is an open access article distributed under the terms and conditions of the Creative Commons Attribution (CC-BY) license (http:/ / creativecommons.org/licenses/by/4.0/). 